\title{
Rapid Induction of Ageing Character in Brandy Products. Ageing and General Overview
}

\author{
F.P. van Jaarsveld ${ }^{*}$, S. Hattingh ${ }^{2}$ \\ (1) ARC Infruitec-Nietvoorbij**, Private Bag X5026, 7599 Stellenbosch, South Africa \\ (2) Department of Medical Physiology, Stellenbosch University, PO Box 19063, Tygerberg 7505, South Africa
}

Submitted for publication: March 2012

Accepted for publication: June 2012

Key words: Unmatured and matured pot-still brandy, oak wood, brandy quality, flavour compounds, maturation

\begin{abstract}
Ageing is one of the most important and most costly factors determining the quality of distilled beverages. As part of a broader study that investigated techniques for the rapid induction of a desirable ageing character in brandy products, the effect of maturation for eight months at room temperature and below $0^{\circ} \mathrm{C}$ in glass bottles, and the relationship/correlation between treatment, chemical composition or wood-derived congener concentrations and pot-still brandy sensory quality, are reported on. Extracts representing different oak types (American or French), levels of toasting, suppliers (i.e. cooper or commercial), types of medium (ethanol or water), concentration types (open or reduced pressure) and concentration levels (by 45, 65 or 85\%) were added to pot-still spirit and stored for eight months in glass containers. Matured and unmatured (control) pot-still brandy samples were analysed for wood-derived compounds by means of HPLC and GC. The different treatments brought about chemical changes with a noticeable impact on the acceptability of oak extracts and the overall quality of pot-still brandies. Through application and selection of the correct oak type and treatment combinations, it therefore was possible to rapidly produce good quality brandies without the use of expensive oak barrels. Maturation in glass bottles had a lesser impact on further improvement of the final product, not the same as the reported improvement from ageing in wooden barrels. The production of good quality brandies and the rapid induction of the ageing character through certain treatment combinations, with little need for further maturation, therefore was achieved in glass. The complexity of brandies aged in glass rather than wooden barrels might be different, since ageing in wooden barrels brings about all the characteristics, complexities and flavours that characteristically evolve over time under the more oxidative conditions in wooden barrels. Future research should focus on a combination of both technologies, using certain oak treatment combinations together with traditional barrel maturation for the improvement and rapid induction of the ageing character in brandy products.
\end{abstract}

\section{INTRODUCTION}

A wide range of distilled beverages, including whisky and brandy, continue to be matured in oak barrels. During maturation, a range of physical and chemical interactions take place between the barrel, the surrounding atmosphere and the maturing spirit. These transform the colour, flavour and composition of the beverage. The effects of, and the time required for, maturation are highly variable, and are influenced by a wide range of factors, such as the distillate, the size, origin of the wood and treatment of the barrel, and the maturation environment. The change in flavour of the maturing spirits is due to changes in the composition and concentration of compounds influencing the taste and aroma, and may be caused by (1) direct extraction of wood compounds, (2) decomposition of wood macromolecules and subsequent extraction, (3) reactions between wood components and constituents of the raw distillate, (4) reactions involving only wood extractables, (5) reactions involving only distillate components, and (6) the evaporation of volatile compounds. As our understanding of the process has improved, there has been increasing interest in methods to predict, control and simulate the effects of maturation.

Depending on their respective concentrations, different wood-derived compounds confer different aromas/flavour that influence the quality of brandy (Table 1). Cis- and transoak lactones have an aroma-likeness, giving off aromas with low but different flavour perception thresholds, adding to the quality of brandy. Methyl-octalactone at low concentrations, as characteristically found in French oak, confers a spicy aroma, whereas at the higher concentrations characteristic of

\footnotetext{
** The Fruit, Vine and Wine Institute of the Agricultural Research Council

*Corresponding author: e-mail: VjaarsveldF@arc.agric.za

Acknowledgements: The authors wish to thank the Agricultural Research Council and the South African Wine Industry (Winetech) for financial support. Special thanks to Ms Mvan der Rijst, for the statistical analysis of the data; Dr N Jolly, for assistance in the compilation of the brandy evaluation scorecards; and Mr M Blom at the Distell Group Limited laboratory and Mr L Ellis at the Stellenbosch University, for the chemical analysis
} 
TABLE 1

Aroma of different wood-derived compounds

\begin{tabular}{|c|c|c|}
\hline Compound & Aroma & Reference \\
\hline Cis-/Trans oak lactone(s) & $\begin{array}{l}\text { Fresh oak wood (woody), } \\
\text { sweet, } \\
\text { coconut, } \\
\text { celery, } \\
\text { spicy }\end{array}$ & $\begin{array}{l}\text { Lebrun, 1991; Piggott et al., 1993; Sefton et al., } \\
\text { 1993; Masson et al., 1995; Sefton \& Spillman, } \\
\text { 1995; Mosedale \& Puech, 1998; Godden et al., } \\
\text { 1999; Hale et al., 1999; Sauvageot \& Feuillat, 1999; } \\
\text { Anonymous, 1995; Lee et al., 2000; Masson et al., } \\
\text { 2000; Cerdán et al., } 2002\end{array}$ \\
\hline Eugenol & Cloves & $\begin{array}{l}\text { Sefton et al., 1993; Singleton, 1995; Mosedale \& } \\
\text { Puech, 1998; Feuillat et al., 1999; Spillman et al., } \\
\text { 2004b }\end{array}$ \\
\hline $\begin{array}{l}\text { Vanillin } \\
\text { Vanillin is known to be highly } \\
\text { beneficial to brandy, whisky, } \\
\text { wine, spirits and beverage qual- } \\
\text { ity (Singleton, 1974; Francis et } \\
\text { al., 1992; Reid \& Swan, 1993; } \\
\text { Sefton et al., 1993). }\end{array}$ & Vanilla & Lebrun, 1991; Lee et al., 2000 \\
\hline Guaiacol & Smoky & $\begin{array}{l}\text { Lebrun, 1991; Sefton et al., 1993; Cerdán et al., } \\
2002\end{array}$ \\
\hline 4-Methylguaiacol & Smoky & $\begin{array}{l}\text { Lebrun, 1991; Sefton et al., 1993; Cerdán et al., } \\
2002\end{array}$ \\
\hline 4-Ethylguaiacol & $\begin{array}{l}\text { Smoky, spicy, } \\
\text { floral, cured bacon-like }\end{array}$ & Lebrun, 1991; Cerdán et al., 2002 \\
\hline Furfural & $\begin{array}{l}\text { Almond-like, grainy, } \\
\text { contributes to "hotness" of spirits }\end{array}$ & $\begin{array}{l}\text { Cerdán et al., 2002; Lee et al., 2000; Singleton, } \\
1995\end{array}$ \\
\hline 5-Hydroxymethyl furfural & Odourless & Cerdán et al., 2002 \\
\hline Methylfurfural & Toasted almond & Lebrun, 1991 \\
\hline Phenolic acids & $\begin{array}{l}\text { Contributes to overall bitterness and } \\
\text { astringency }\end{array}$ & Jindra \& Gallander, 1987 \\
\hline $\begin{array}{l}\text { Phenolics: } \\
o \text {-Cresol, } p \text {-cresol }\end{array}$ & $\begin{array}{l}\text { Reduce the harshness of brandy, im- } \\
\text { prove the taste of brandy products, } \\
\text { interact with flavour constituents and } \\
\text { as such have a significant effect on } \\
\text { the perception of food and beverage } \\
\text { flavour }\end{array}$ & $\begin{array}{l}\text { Singleton, 1974; Suomalainen et al., 1974; } \\
\text { Venkataramu et al., 1983; Francis et al., 1992; Jung } \\
\text { et al., } 2000\end{array}$ \\
\hline
\end{tabular}

American oak, an aroma closer to that of coconut is conferred. This feature is utilised by the producers of whiskies and bourbons to enhance a powerful bouquet (Anonymous, 1995; Sefton \& Spillman, 1995; Lee et al., 2000; Masson et $a l ., 2000)$. The "lactone" character of extracts is dominated by the $c$ is-isomer.

The purpose of this study was to investigate conditions that would induce the softer and more rounded, aged character that is typical of a good brandy in a shorter maturation time through the addition of oak wood extracts prepared from oak chips (increased surface/volume ratio) treated in various ways. It is important to know how the chemical compounds evolve in order to obtain more precise data on the ideal period of spirits storage in barrels. In this way, it may be possible to reduce excessively long periods of pot-still brandy maturation, and so help to reduce costs, time and product wastage. Wooden barrels are expensive, requiring complicated and costly maintenance procedures. Evaporation from wooden barrels is higher than from tanks. Also, if wood quality and manufacturing are poor, the barrel can affect the quality of the spirits negatively and lead to loss. The use of alternative oak sources in old barrels or stainless steel tanks, together with oxygenation, has been suggested as a viable alternative. The addition of oak chips to brandy for the purpose of producing beverages with a barrel-aged style has met with some scepticism. A typical criticism is that beverages stored in containers other than the traditional wooden casks do not undergo the slow oxygen uptake associated with barrel ageing. The general lack of information concerning the movement of oxygen into barrels and the mode of action of oxygen add to this concern. Also, more research has been published regarding the use of oak barrels rather than oak chips in the ageing of wines and distilled spirits.

Relatively few studies have directly addressed the problematic relationship between the concentration and composition of wood-derived compounds and the flavour of brandy. This is the fourth in a series of articles, in which the first article focused on the importance of extracts in brandy maturation, the preparation of oak extracts, and the effect 
of different extraction conditions, mediums and suppliers of oak chips on chemical and sensory profiles (Van Jaarsveld et al., 2009a). The second paper discussed the influence of oak type on the sensory and chemical profiles of fortified extracts and unmatured and matured pot-still brandy (Van Jaarsveld et al., 2009b), while the third focused on the impact of toasting on quality and chemical profiles (Van Jaarsveld et al., 2009c). The current overview article deals with the effects of maturation for eight months on, and the correlation between, sensory quality and chemical composition, while interactive aspects of the collected data are also discussed.

\section{MATERIALS AND METHODS}

Materials and Methods have already been described in Part I (Van Jaarsveld et al., 2009a). Briefly, American and French oak chips, representing different levels of toasting and obtained from a cooper and a commercial supplier, were placed in either water or a $55 \%(\mathrm{v} / \mathrm{v})$ ethanol medium and boiled under reflux with backflow cooling for five hours. This was followed by either open concentration, or concentration under reduced pressure using a Buchi rotavapour. Extracts were fortified to $40 \%(\mathrm{v} / \mathrm{v})$. Fortified extracts were added to $70 \%(\mathrm{v} / \mathrm{v})$ pot-still spirit (procured as one batch) at $60 \mathrm{~mL} / \mathrm{L}$ and stored for eight months in glass containers (Schott bottles) at room temperature, or in the case of the controls, below $0^{\circ} \mathrm{C}$. Samples were subjected to sensory and compositional analysis. Selected chemical variables encompassed a wide range of compounds considered to contribute to the flavour of the maturing distillate. Volatile flavour constituents extracted into the distilled spirit from oak chips were separated, identified and quantified by gas chromatography (GC), and the same was done with the non-volatile and less volatile compounds by using high-performance liquid chromatography (HPLC). Fortified (40\%, v/v) extracts were sensorially evaluated in duplicate by a panel of seven judges for acceptability for brandy production by means of a "yes" or "no" response. The number of "yes" scores for each extract evaluated was expressed as a percentage of the total number of evaluations per extract. Pot-still brandy samples were also sensorially evaluated for overall quality by a panel of seven experienced judges. A line method was used, i.e. evaluating the brandy characteristics by marking an unstructured, straight $10 \mathrm{~cm}$ long line. The left- and right-hand ends of the line were indicated by the terms "not detectable" and "prominent" respectively.

Pot-still brandies from the various treatments were compared for differences in chemical composition and sensory properties. Correlation analyses were performed to test linear relationships between the sensory variables and the chemical variables on the one hand, and between the chemical variables or sensory descriptors on the other hand.

The dataset was first evaluated using univariate methods. Since not all of the 25 volatile and non-volatile components necessarily served as classifiers, an initial univariate analysis was conducted to identify which components would have the greatest discriminating power. Analysis of variance was conducted on the basis of the following factors: extraction medium, toast level, concentration type and level, oak type and supplier. The variables measured were subjected to analysis of variance (ANOVA), using the general linear

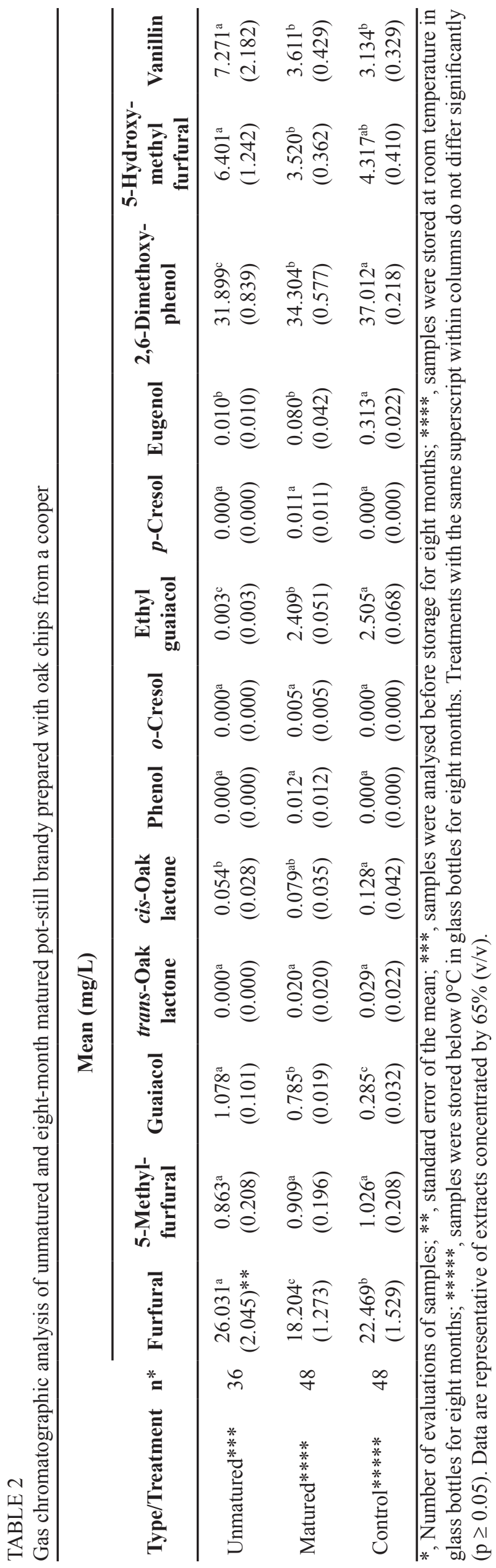



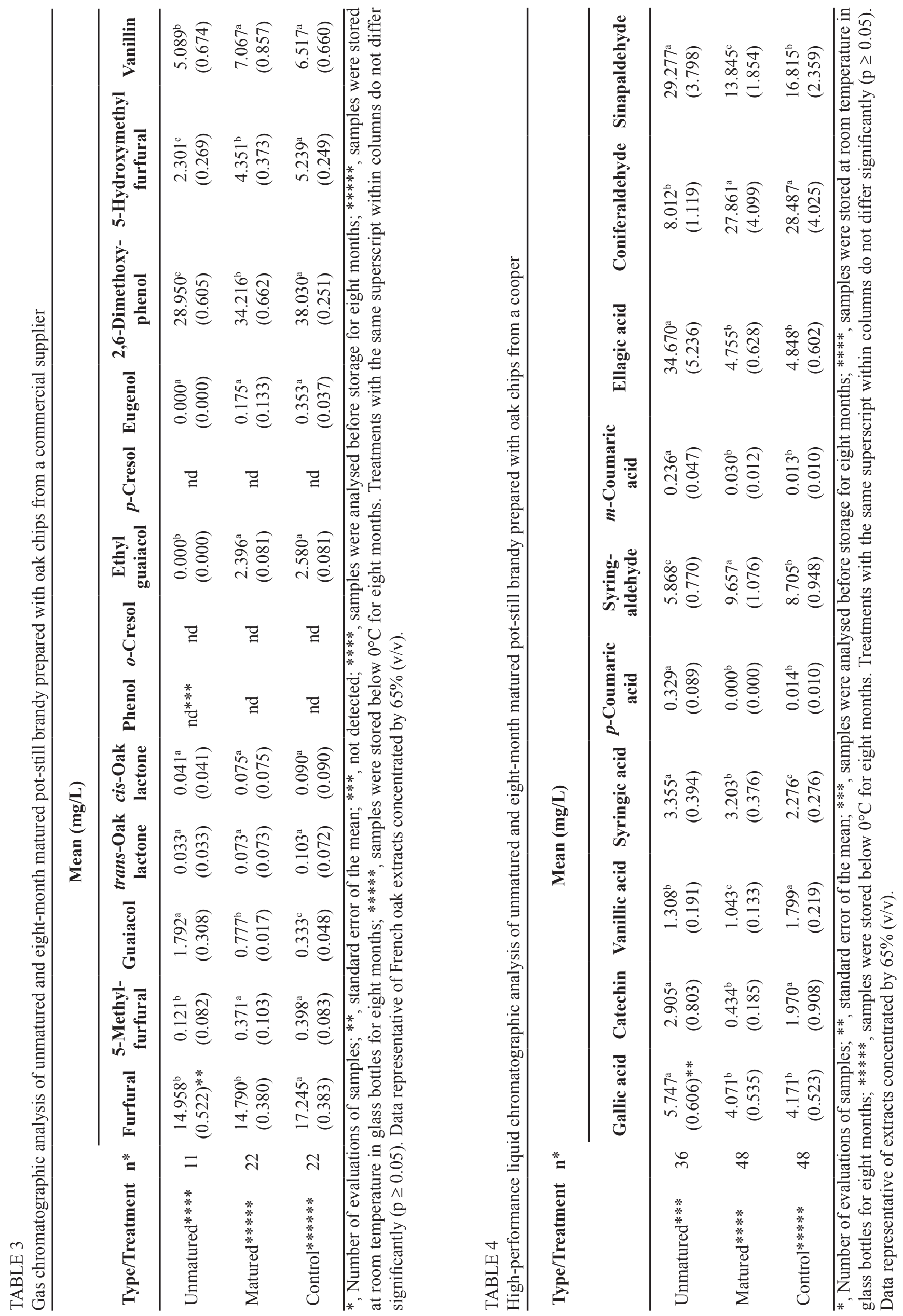
models (GLM) procedure of SAS statistical software version 8.2 (SAS Institute Inc., Cary, NC, USA) (SAS, 2000). The Shapiro-Wilk test was performed to test for normality (Shapiro \& Wilk, 1965). Fisher's t-least significant difference (LSD) was calculated at the $5 \%$ probability level to facilitate a comparison between treatment means. Values that differed at $\mathrm{p} \leq 0.05$ were considered to be significantly different.

Principal component analysis (PCA) and discriminant analysis (DA) were used as pattern recognition tools. PCA was used prior to any assumptions for preliminary data analysis to provide a partial visualisation of the dataset and to permit a primary evaluation of the between-category similarity. Based on the fact that the selection of key features of the dataset may offer an increased reliability of the mathematical outcome (Li \& Hardy, 1999), discriminant analysis by the forward stepwise method was used to select the most powerful discriminators (variables most effective at separating the factors). Visualisation of the classification and between-group differentiation results was achieved by projecting the set of discriminant scores onto the twodimensional space defined by both discriminant functions. The ellipses around each grouping represented the 95\% confidence limit for that grouping. All computations were carried out using the package XLSTAT 2008 [Pro] (Win).

\section{RESULTS AND DISCUSSION}

The significance of the effects of the different treatments and their interactions were determined by ANOVA (Tables 2 to 12). Considering the large number of extractions performed, their sensory evaluations, the number of components analysed by GC and HPLC, and the number of treatment combinations, too many results were obtained for a fully inclusive account to be presented here. Representative data are shown in Figures 1 to 7 and Tables 2 to 13 .

\section{Ageing}

Little difference $(p \geq 0.05)$ in sensory quality was observed between matured pot-still brandy aged for eight months in glass bottles at room temperature, and pot-still brandy stored in glass bottles at subzero temperature (Fig. 1). In this latter treatment the effects of ageing should theoretically be reduced or minimised due to slower reaction conditions. However, significant differences in concentration were observed for the various flavour compounds (Tables 2 to 5).

Discriminant analysis separated pot-still brandy samples aged for eight months in glass bottles at room temperature from those stored in glass at subzero temperature (Fig. 2). However, separation based on GC and HPLC between samples matured at the two storage temperatures (Fig. 2) was less pronounced and overlapped more in terms of the $95 \%$ confidence limits, with some heterogeneity in the boundary area between the two separated clusters, when compared to differences in maturation times (unmatured versus matured), where the groups were separated completely into distinct clusters (Fig. 3). Clusters related to ageing were separated mainly by the first PC in discriminant analysis (Figs 3 and 4).

Increases in the "mature" sensory characteristics, i.e. woody, were also observed in samples in the presence of wood and those stored at room temperature, as opposed to samples with no extracts and stored below $0^{\circ} \mathrm{C}$ (Fig. 5). These results corresponded to literature reports on the effect of maturation and increased wood-derived flavour notes or "mature" sensory characteristics (Piggott et al., 1993). Similar significant $(\mathrm{p} \leq 0.05)$ increases were also observed for the "toasted" sensory character (Fig. 5). Using sensory descriptive analysis, Francis et al. (1992) reported oak-aged samples, compared to glass-aged control wines, to show a significant increase in the intensity of spicy, vanilla and oak-blend attributes, with a decrease in vegetative character.

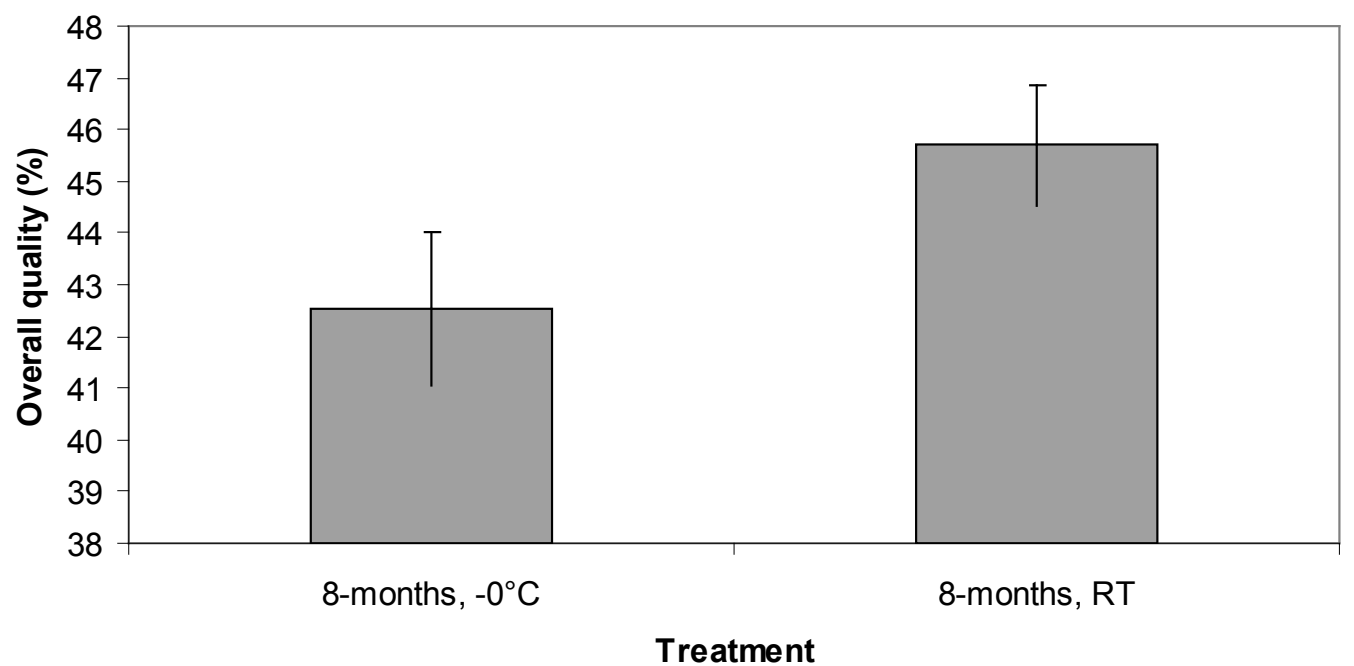

FIGURE 1

Comparison of overall sensory quality between eight-month matured test (RT) and control (below $0^{\circ} \mathrm{C}$ ) matured pot-still brandies prepared with oak wood extracts. Test and control samples were stored at room temperature and below $0^{\circ} \mathrm{C}$ in glass bottles for eight months respectively. Extracts were prepared from chips of different types of oak (American and French) obtained from a cooper and commercial suppliers and subjected to various treatments. Open concentration of extracts was performed in a $5 \mathrm{~L}$ flask on a heating mantle. Reduced pressure concentration was performed under vacuum on a rotavap. Extractions were performed in either water or ethanol medium. Oak toast levels: untoasted, medium, heavy, special, premium, toasted and light. Extracts concentrated by $65 \%(\mathrm{v} / \mathrm{v})$ of the original volume. 
Factors that might contribute to, or cause, sensory differences between samples are volatile acidity and changes due to the level of oxygen exposure (Wilker \& Gallander, 1988).

Maturation time also had an effect on the occurrence and concentration of different compounds. Insignificant $(\mathrm{p} \geq 0.05)$ and significant $(p \leq 0.05)$ changes (increased or decreased) in the concentrations of volatile and less-volatile compounds of eight-month matured as compared to unmatured pot-still brandy, prepared with oak chips, were observed with time of ageing in glass (Tables 2 to 5). Increased as well as decreased and unchanged concentrations of the different volatile and less-volatile wood-derived compounds have also been reported by various authors for spirits aged in new or reused American and French oak wood for different storage periods (Baldwin et al., 1967; Otsuka et al., 1974; Onishi et al., 1977; Jindra \& Gallander, 1987; Puech, 1987; Wilker \& Gallander, 1988; Litchev, 1989; Clyne et al., 1993; Piggott et al., 1993; Sefton et al., 1993; Venter, 1994; GómezCordovés \& Bartolomé, 1999; Cerdán et al., 2002). Changes in concentration of the different compounds with time of ageing in this study and those reported by other workers in the field were not always the same; however, differences in sensory and chemical evolutionary changes between spirits aged in glass in this study and spirits aged in wood in reported studies by other workers are to be expected. The different studies also vary in their respective approaches/ methodologies.

Benzoic (vanillin, syringaldehyde) and cinnamic (coniferaldehyde, sinapaldehyde) aldehydes (Puech, 1984), which are produced by the main process of brandy ageing, viz. hydroalcoholic processes at room temperature were present in all the aged samples in this study, as has also been reported by other authors (Baldwin et al., 1967).

Phenolics such as $o$-cresol and $p$-cresol were found in low

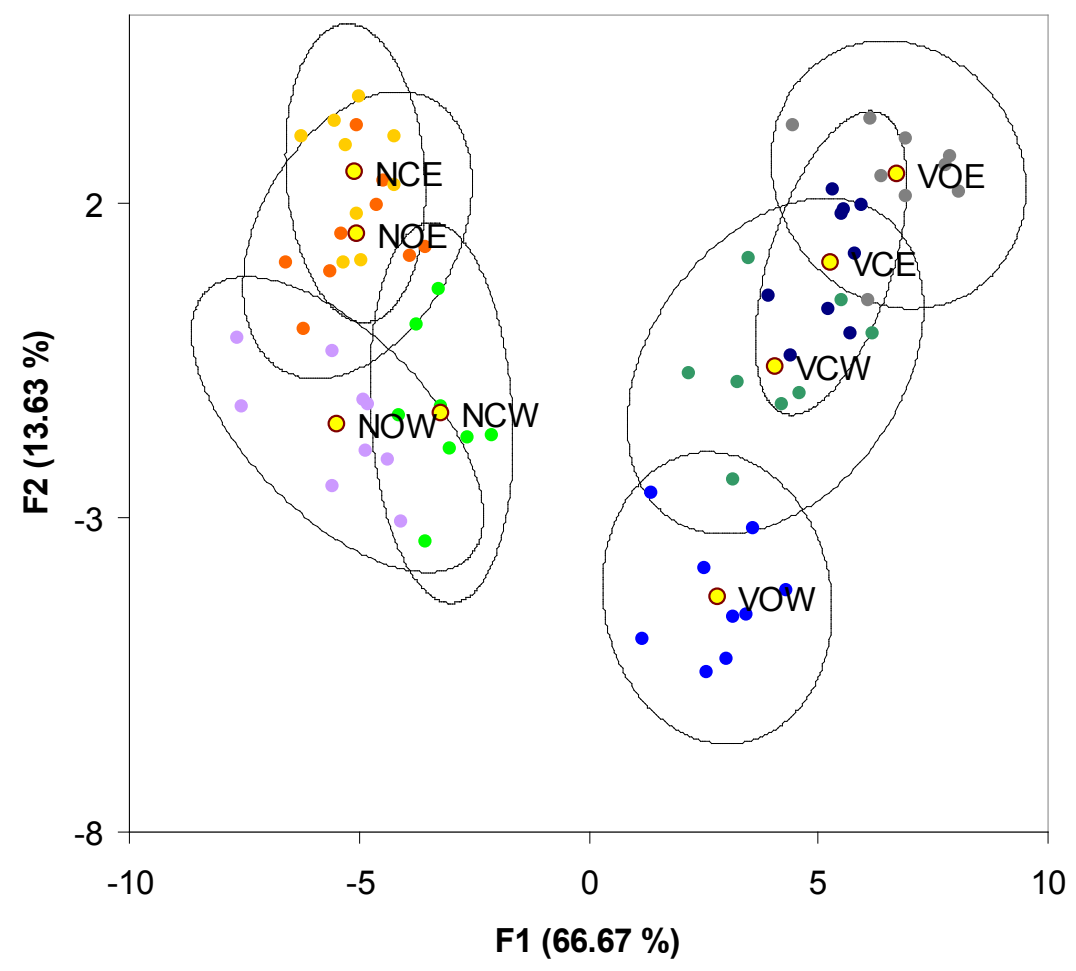

\begin{tabular}{|c|c|c|c|}
\hline $\begin{array}{l}\text { - NOE } \\
\text { - VOW }\end{array}$ & $\begin{array}{l}\text { - } \mathrm{NOW} \\
\text { - } \mathrm{VCE}\end{array}$ & $\begin{array}{l}\text { NCE } \\
\text { VCW }\end{array}$ & $\begin{array}{l}\text { - NCW } \quad \text { VOE } \\
\text { o Centroids }\end{array}$ \\
\hline
\end{tabular}

FIGURE 2

Plot of discriminant scores of the first two discriminant factors (F1, F2) of matured pot-still brandies for the treatment classes frozen $(\mathrm{V})$ /not frozen $(\mathrm{N})$ x open $(\mathrm{O})$ /reduced pressure $(\mathrm{C}) \mathrm{x}$ ethanol $(\mathrm{E}) /$ water $(\mathrm{W})$, defined by the variables herbaceous, woody, overall sensory quality, 5-methylfurfural, 2,6-dimethoxyphenol, 5-hydroxymethyl furfural, gallic acid, p-hydroxybenzoic acid, syringic acid, syringaldehyde, ellagic acid, coniferaldehyde, sinapaldehyde, fruity, toasted, sweet associated, other positive, other negative, furfural, guaiacol, trans-oak lactone, cis-oak lactone, ethyl guaiacol, eugenol, vanillin, protocatechuic acid, catechin, vanillic acid, m-coumaric acid, phenol, o-cresol, p-cresol and p-coumaric acid. Only the 65\% (v/v) concentration was considered in the statistical evaluation. Pot-still brandies were prepared with oak wood extracts prepared from chips of different types of differently toasted oak obtained from a cooper and a commercial supplier and subjected to various treatments, as described in the legend to Figure 1, to extract the wood components, and stored for eight months at room temperature or below $0^{\circ} \mathrm{C}$. Discrimination in the direction of the first discriminant function is associated mainly with the parameters 2,6-dimethoxyphenol, p-hydroxybenzoic acid, guaiacol, eugenol and protocatechuic acid, whereas discrimination in the direction of the second discriminant function is associated mainly with the parameters woody, 5-methylfurfural, ellagic acid and coniferaldehyde. The first discriminant function separates brandies according to the treatment classes frozen (V)/not

frozen $(\mathrm{N})$. The second discriminant function separates brandies according to treatment classes ethanol (E)/water (W). 


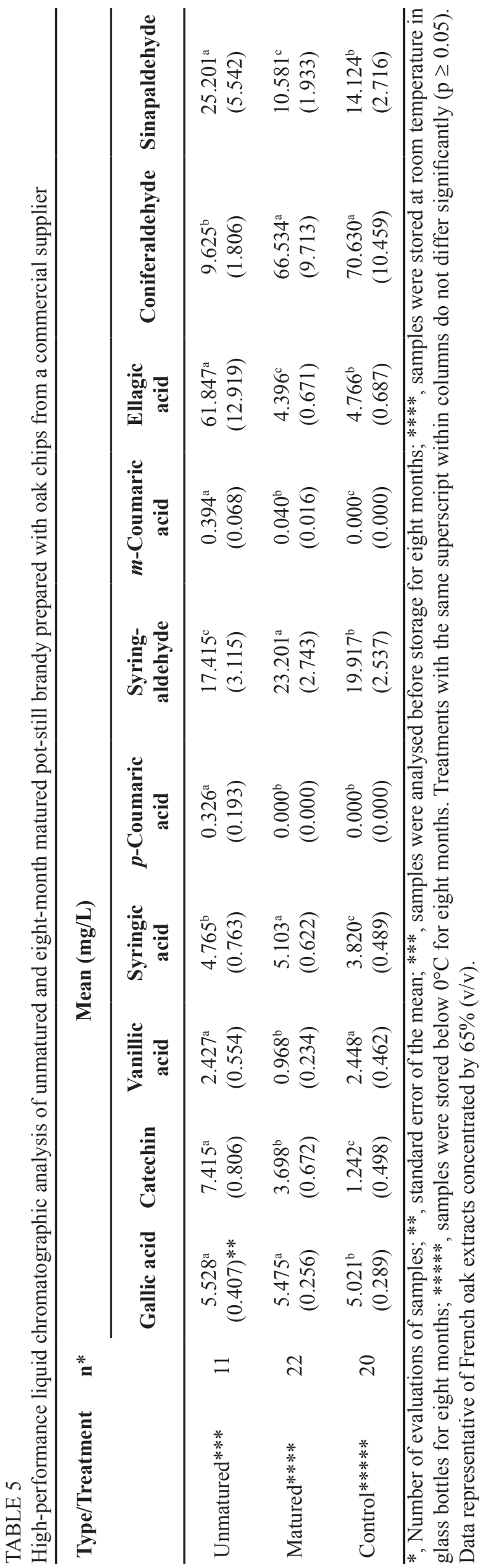

concentrations throughout the course of maturation (Tables 2 and 3); low concentrations of these compounds were also reported by Cerdán et al. (2002). Phenolic compounds are known to dissolve from the wood into the alcohol during the maturation of distilled spirits (Suomalainen \& Nykänen, 1972). Decreased gallic and ellagic acid concentrations in matured (eight-month storage period in glass containers) compared to unmatured pot-still brandies (Tables 4 and 5) can be attributed to the conversion of gallic acid to other phenolic compounds, viz. phenolic acids and aldehydes, during ageing (Venter, 1994) or, in part, due to limited oxidation (oxygen in headspace - glass bottles not completely filled) and degradation to breakdown products. Increased, as well as decreased, gallic acid concentrations upon oxygenation over time have been reported (De Beer et al., 2008). Also, in matured distilled spirits the oak tannins become hydrolysed and, although gallic acid remains, the ellagic derivatives will precipitate (Singleton, 1995). Wilker and Gallander (1988) reported little to no change in concentration of phenolic acids, except for gallic acid, which increased upon storage of up to ten weeks in stainless steel tanks with chips (and in new and used oak barrels). In contrast to findings by Jindra and Gallander (1987), but in accordance with Singleton (1974), the free and relatively nonvolatile phenolic acids under study appeared to have an effect on differences in the sensory quality of matured pot-still brandies (Tables 6 and 7). The higher concentrations of the phenolic gallic acid in this study can be attributed to different oak extraction methods and media, as well as ageing periods. Unlike freely extractable phenols, these compounds may be chemically bound to the wood structure, and the amount extracted would depend upon the rate of hydrolysis of the bound forms as well as the ageing period. Hydrolysis can be a limiting step in the transfer of phenols from wood into spirits. Phenols themselves might also undergo changes as a result of limited oxidation. The eight-month maturation period in this study is relatively short, and it is expected that the chemical changes and changes in sensory characteristics would continue during further maturation.

Numerous literature reports discuss the impact of ageing. These investigations, however, were done on spirit aged in wood. Few report on ageing in glass. Ageing effects in wood and glass will be somewhat different, as shown by the present study. In the present study, good quality extracts and glass-matured pot-still brandies were produced from oak chips subjected to different treatment combinations. Agerelated statistical differences in chemistry, however, did not translate into significant sensory differences. Certain changes are intimately related to oxidative processes that develop over time in wood, and were not possible in this study, where ageing took place in the presence of oak extracts in closed glass containers over eight months. Baldwin et al. (1967) and De Smedt and Liddle (1978) reported that changes such as the reported increased concentrations of esters, aldehydes, furfural, tannins and dissolved solids occurring in wooden barrels could not be duplicated by storage in glass. De Smedt and Liddle (1978) found a compound in Cognac stored in wood that was absent in all samples stored in glass for a period of up to five years, and in samples of freshly distilled spirits. Sauvageot and Feuillat (1999) reported that bottle 
ageing had little effect sensorially up to 12 and 30 months of ageing. Singleton (1974) found that the flavour intensity of American oak extracts did not change appreciably during nine years of storage in glass bottles, with extracted solids and phenol content remaining constant.

\section{Correlation analysis}

Similar to the findings of other studies, this study was able to correlate an increasing concentration of known oak-derived aroma compounds with perceived changes in intensity of sensory descriptors for extracts and matured pot-still brandy.

\section{Unmatured samples}

Compounds that correlated significantly ( $\mathrm{p}<0.0001)$, in unmatured pot-still brandy only, from both cooper- and commercially-prepared oak chips, were: vanillic acid and syringic acid, vanillic acid and syringaldehyde, vanillic acid and ellagic acid, vanillic acid and coniferaldehyde, and vanillic acid and sinapaldehyde. Due to the large volume of data, a representative table of the statistical relationships between compounds is given for matured samples under the next heading, "Eight-month matured pot-still brandies".

\section{Eight-month matured pot-still brandies}

Strong and significant correlations generally exist between several sensory descriptors for matured pot-still brandies prepared with either American or French oak chips obtained from a cooper or commercial supplier and stored frozen or at room temperature. Representative data of American oak chips obtained from a cooper and stored at room temperature is given in Table 8. Herbaceous correlated significantly with fruity, sweet, and other positive and negative aromas (cooper). Fruity correlated significantly with sweet and other positive aromas, as well as with overall quality. Oak chips

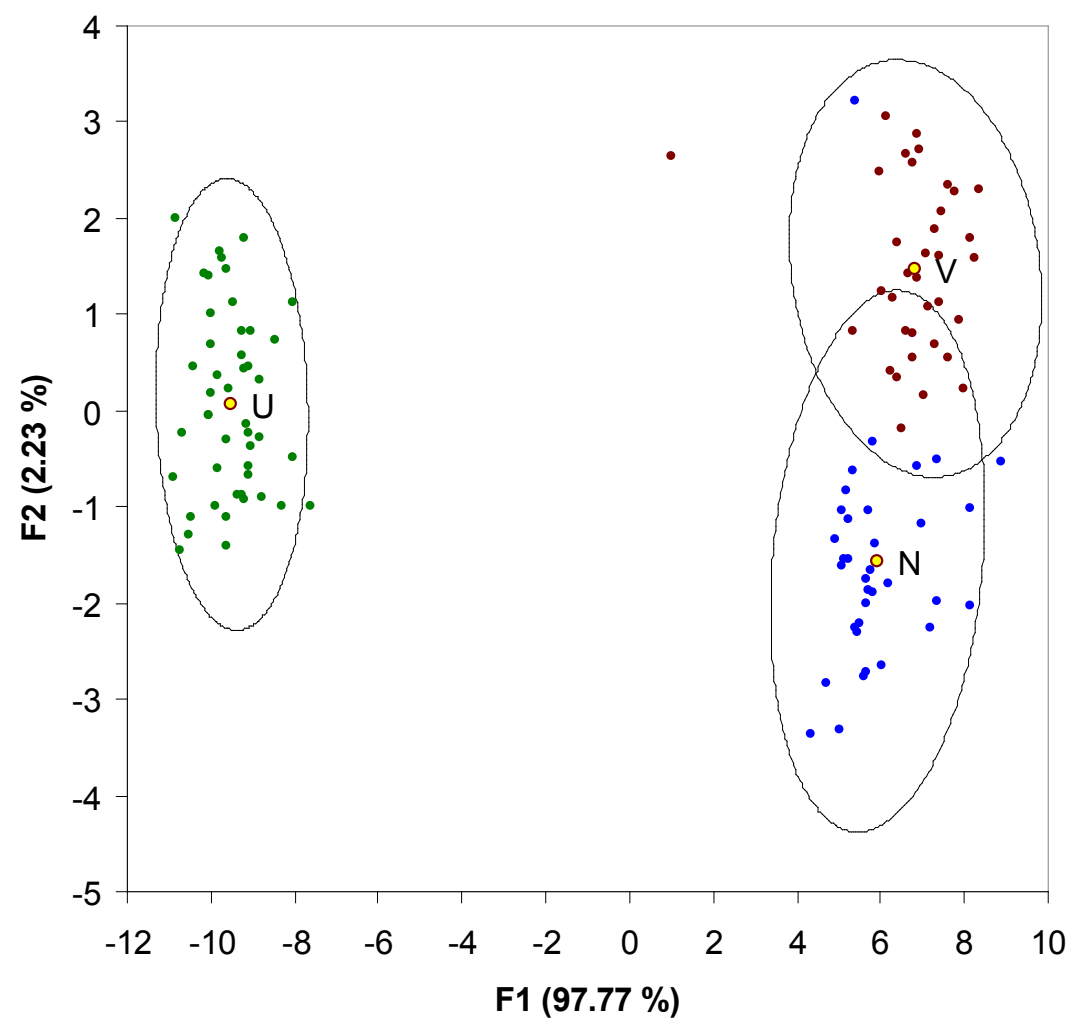

$\cdot \mathrm{N} \cdot \mathrm{U} \cdot \mathrm{V} \circ$ Centroids

FIGURE 3

Plot of discriminant scores of the first two discriminant factors (F1, F2) of matured and unmatured pot-still brandies for the treatment classes unmatured $(\mathrm{U}) \times$ matured below $0^{\circ} \mathrm{C}(\mathrm{V}) \times$ matured at room temperature $(\mathrm{N})$, defined by the variables furfural, 5-methylfurfural, guaiacol, trans-oak lactone, cis-oak lactone, phenol, o-cresol, ethylguaiacol, p-cresol, eugenol, 2,6-dimethoxyphenol, 5-hydroxymethyl furfural, vanillin, gallic acid, catechin, vanillic acid, syringic acid, p-coumaric acid, syringaldehyde, m-coumaric acid, ellagic acid, coniferaldehyde and sinapaldehyde. Only the 65\% (v/v) concentration was considered in the statistical evaluation. Pot-still brandies were prepared with oak wood extracts prepared from chips of different types of differently toasted oak obtained from a cooper and a commercial supplier and subjected to various treatments, as described in the legend to Figure 1, to extract the wood components, and stored for eight months at room temperature or below $0^{\circ} \mathrm{C}$. Discrimination in the direction of the first discriminant function is associated mainly with the parameters guaiacol, ethylguaiacol, eugenol, 2,6-dimethoxyphenol, p-coumaric acid, m-coumaric acid, ellagic acid and coniferaldehyde, whereas discrimination in the direction of the second discriminant function is associated mainly with the parameters furfural, guaiacol, eugenol, 2,6-dimethoxyphenol and vanillic acid. The first discriminant function separates brandies according to the treatment classes unmatured $(\mathrm{U}) /$ matured $(\mathrm{N}, \mathrm{V})$. 


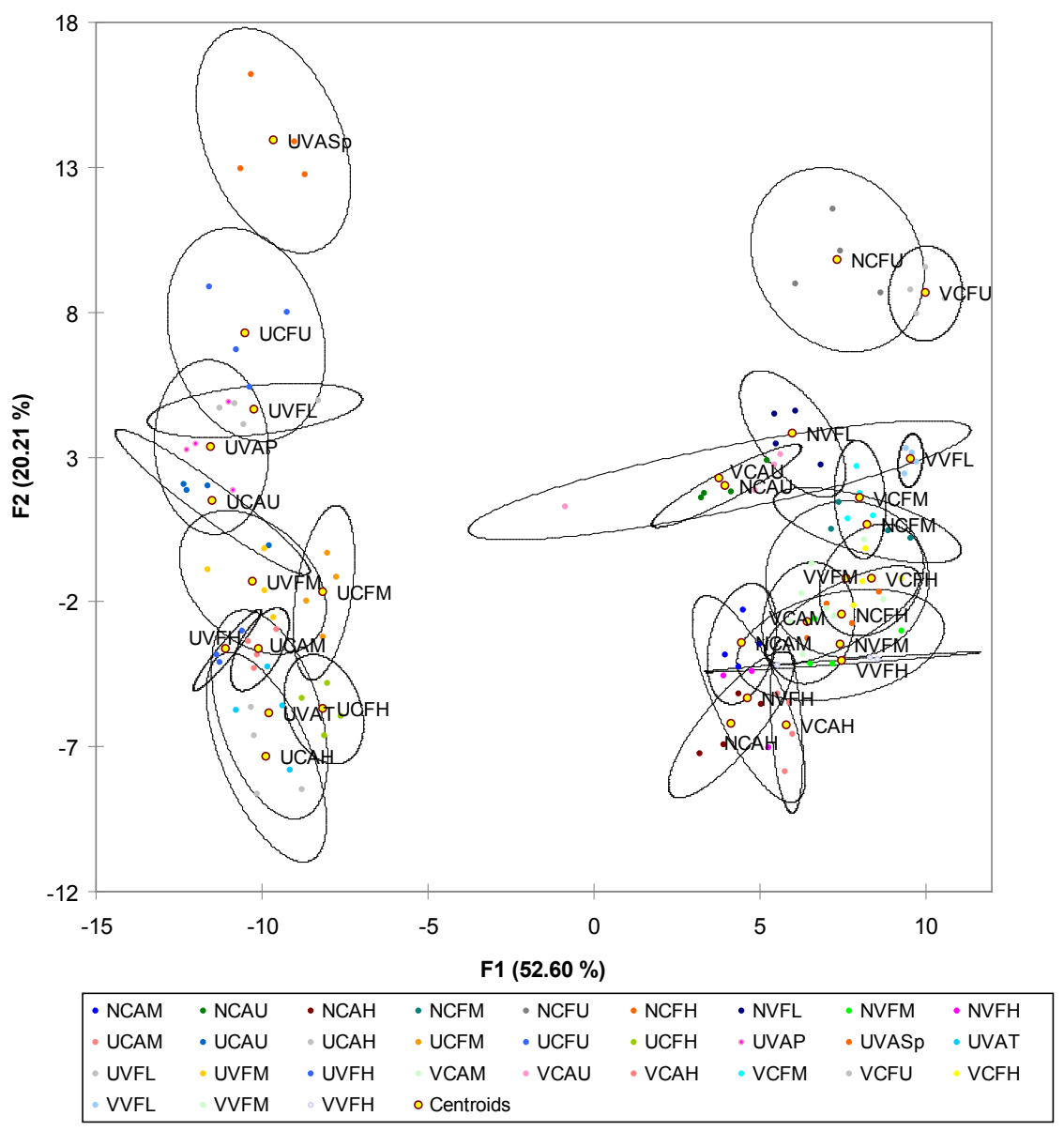

FIGURE 4

Plot of discriminant scores of the first two discriminant factors (F1, F2) of unmatured and matured pot-still brandies for the treatment classes NCAM, NCAU, NCAH, NCFM, NCFU, NCFH, NVFL, NVFM, NVFH, UCAM, UCAU, UCAH, UCFM, UCFU, UCFH, UVAP, UVASp, UVAT, UVFL, UVFM, UVFH, VCAM, VCAU, VCAH, VCFM, VCFU, VCFH, VVFL, VVFM and VVFH, defined by the variables furfural, 5-methylfurfural, guaiacol, trans-oak lactone, cis-oak lactone, phenol, o-cresol, p-cresol, ethyl guaiacol, eugenol, 2,6-dimethoxyphenol, 5-hydroxymethyl furfural, vanillin, gallic acid, catechin, vanillic acid, syringic acid, p-coumaric acid, syringaldehyde, m-coumaric acid, ellagic acid, coniferaldehyde and sinapaldehyde. Treatment abbreviations: NCAM: room temperature, cooper, American, medium; NCAU: room temperature, cooper, American, untoasted; NCAH: room temperature, cooper, American, heavy; NCFM: room temperature, cooper, French, medium; NCFU: room temperature, cooper, French, untoasted; NCFH: room temperature, cooper, French, heavy; NVFL: room temperature, commercial, French, light; NVFM: room temperature, commercial, French, medium; NVFH: room temperature, commercial, French, heavy; UCAM: unmatured, cooper, American, medium; UCAU: unmatured, cooper, American, untoasted; UCAH: unmatured, cooper, American, heavy; UCFM: unmatured, cooper, French, medium; UCFU: unmatured, cooper, French, untoasted; UCFH: unmatured, cooper, French, heavy; UVAP: unmatured, commercial, American, premium; UVASp: unmatured, commercial, American, special; UVAT: unmatured, commercial, American, toasted; UVFL: unmatured, commercial, French, light; UVFM: unmatured, commercial, French, medium; UVFH: unmatured, commercial, French, heavy; VCAM: below $0^{\circ} \mathrm{C}$, cooper, American, medium; VCAU: below $0^{\circ} \mathrm{C}$, cooper, American, untoasted; VCAH: below $0^{\circ} \mathrm{C}$, cooper, American, heavy; VCFM: below $0^{\circ} \mathrm{C}$, cooper, French, medium; VCFU: below $0^{\circ} \mathrm{C}$, cooper, French, untoasted; VCFH: below $0^{\circ} \mathrm{C}$, cooper, French, heavy; VVFL: below $0^{\circ} \mathrm{C}$, commercial, French, light; VVFM: below $0^{\circ} \mathrm{C}$, commercial, French, medium; VVFH: below $0^{\circ} \mathrm{C}$, commercial, French, heavy. Only the $65 \%(\mathrm{v} / \mathrm{v})$ concentration was considered in the statistical evaluation. Pot-still brandies were prepared with oak wood extracts prepared from chips of different types of differently toasted oak obtained from a cooper and a commercial supplier and subjected to various treatments, as described in the legend to Figure 1, to extract the wood components, and stored for eight months at room temperature or below $0^{\circ} \mathrm{C}$. Discrimination in the direction of the first discriminant function is associated mainly with the parameters guaiacol, ethyl guaiacol, eugenol, 2,6-dimethoxyphenol, $\mathrm{m}$-coumaric acid, ellagic acid and coniferaldehyde, whereas discrimination in the direction of the second discriminant function is associated mainly with the parameters 5-hydroxymethyl furfural, gallic acid, syringic acid, syringaldehyde, m-coumaric acid and sinapaldehyde. The first discriminant function separates brandies according to the treatment classes unmatured (U)/matured

$(\mathrm{N}, \mathrm{V})$. The second discriminant function separates brandies according to the treatment class toasting (U, M, H, L, P, Sp). 
are known to impart fruity aromas to beverages (Wilker \& Gallander, 1988). Woody and toasted aromas correlated significantly. Toasted correlated significantly with sweet aromas (cooper). Sweet-associated aromas correlated significantly with other positive aromas and other positive aromas with overall quality. Sauvageot and Feuillat (1999) also reported positive correlations between the descriptors woody and toasted.

Furfural, 5-methylfurfural, 5-hydroxymethyl furfural and vanillin are generally more strongly and significantly correlated with the woody and toasted characters in eightmonth matured pot-still brandy and, to a lesser extent, in American oak from a cooperage, also with sweet associated flavours; with varying (positive and negative) correlations with overall sensory quality (Tables 9 and 10). Guaiacol, generally with American oak from a cooperage, was positively correlated with overall sensory quality in eightmonth matured pot-still brandy. Furfural, vanillin and lactones are all considered sensorially important oak wood compounds. The concentrations of vanillin in this study, being higher in toasted samples, i.e. 0 to $63 \mathrm{mg} / \mathrm{L}$, average $5.70 \mathrm{mg} / \mathrm{L}$ (unmatured) and 0 to $16.79 \mathrm{mg} / \mathrm{L}$, average 4.32 $\mathrm{mg} / \mathrm{L}$ (matured), are well above the concentrations of 0.1 to $0.3 \mathrm{mg} / \mathrm{L}$ reported by Sefton et al. (1993) and therefore, in contrast to their findings, do play a role in the flavour of most of the pot-still brandies (Table 9). "Vanilla oak" character is often seen to be an important and desirable feature of a beverage matured in new wood; however, the perception of this character may be due to the influence of oak components other than vanillin (Sefton et al., 1993; Sefton \& Spillman, 1995). Significant correlations between lactone and sweetassociated aromas were evident in eight-month matured potstill brandies prepared with chips from a commercial supplier (Table 10). Sensory descriptors in eight-month matured pot-still brandies generally correlated either positively (fruity, woody, toasted and positive aromas) or negatively (herbaceous, other negative) with the concentration of cis-lactone. A strong correlation between preference and complementary effect between fruity characters and a (high) concentration of cis-oak lactone (also being aromaactive in many fruits) has been reported by some authors (Sefton \& Spillman, 1995; Godden et al., 1999). Except for sweet-associated aromas as referred to above, and similarly to what was reported by Sauvageot and Feuillat (1999), a strong correlation was not found between trans-oak lactone and sensory quality descriptors, which tends to confirm that this isomer does not influence the descriptors studied. Cisoak lactone is reported to be more fragrant than trans-oak lactone (Otsuka et al., 1974). Also, the threshold value of the trans isomer could be more dependent on the nature of the medium than the cis isomer. Therefore the effect of the trans isomer on flavour may vary with the properties of the wine/ spirits, such as the degree of alcohol, and the concentration and composition of phenolic compounds (Sauvageot \& Feuillat, 1999).

Generally, the less volatile compounds are mostly positively and significantly correlated with the woody, toasted, sweet-associated and positive characters, and with overall sensory quality in American oak (Table 6), with negative correlations observed in some cases in French oak (Table 7).

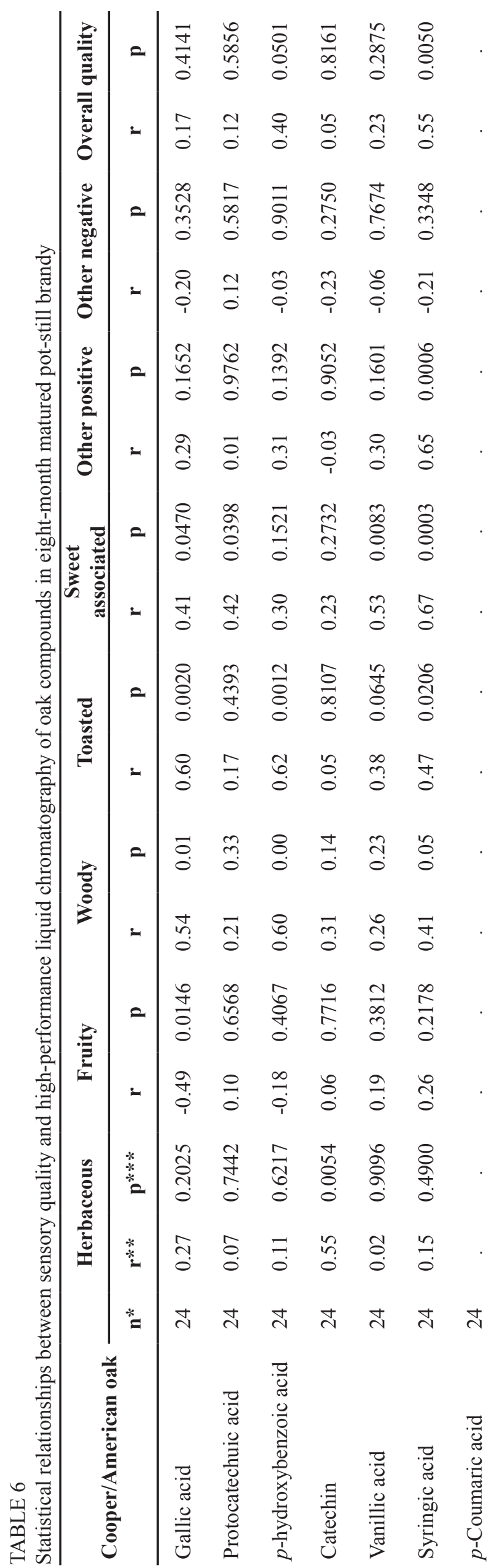




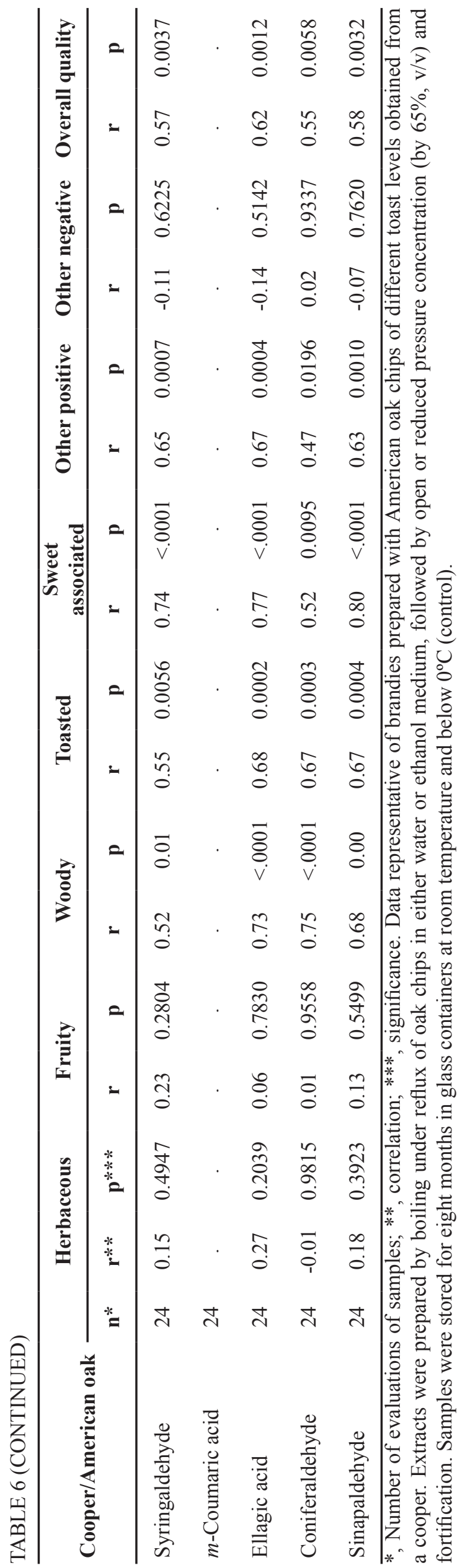

The less volatile compounds ellagic acid, coniferaldehyde, sinapaldehyde, syringaldehyde, syringic acid, gallic acid and $p$-hydroxybenzoic acid correlated most significantly with the woody and toasted flavours of eight-month matured potstill brandy. Syringaldehyde concentration also correlated (more prominent for American oak) with overall quality. Reid and Swan (1993) also reported higher concentrations of syringaldehyde in good quality spirits. The oak wood compound syringaldehyde is considered sensorially important (Singleton, 1974; Francis et al., 1992; Sefton et al., 1993). In contrast to the report by Jindra and Gallander (1987), the free and relatively nonvolatile phenolic acids under study appeared to have an effect on differences in the sensory quality of oak-aged pot-still brandies (Tables 6 and 7). Wilker and Gallander (1988) reported that an increase in gallic acid may indicate a decrease in astringency.

Compounds in unmatured and eight-month matured potstill brandies, prepared with oak chips from either a cooper or a commercial supplier, that correlated significantly $(\mathrm{p}<$ 0.0001 ) and positively were: furfural and 5-methylfurfural, 5-hydroxymethyl furfural and vanillin, syringic acid and syringaldehyde, syringic acid and ellagic acid, syringic acid and coniferaldehyde, syringic acid and sinapaldehyde, syringaldehyde and ellagic acid, syringaldehyde and coniferaldehyde, syringaldehyde and sinapaldehyde, ellagic acid and coniferaldehyde, ellagic acid and sinapaldehyde, and coniferaldehyde and sinapaldehyde. Due to the large volume of data, a representative table of the statistical relationships between compounds is given only for matured pot-still brandies from cooper-prepared oak chips (Table 11).

\section{Treatment interactions}

Significant interaction $(p \leq 0.05)$ effects on different subgroups of the data (i.e. cooper/American and French oak $/ 65 \%(\mathrm{v} / \mathrm{v})$ concentration level, commercial supplier/ French oak $/ 65 \%$ (v/v) concentration level, and cooper and commercial supplier/French oak/65\% (v/v) concentration level) were determined statistically. The ANOVA showed significant interactions $(\mathrm{p} \leq 0.05)$ between treatments (Table 12). Representative examples are given in Figs 6 and 7.

\section{Overall trends and observations}

As evident from Van Jaarsveld et al. (2009a, 2009b, 2009c) and from reports in the literature (Williams, 1983; Singleton, 1995), many components are common to all matured distilled beverages, varying only quantitatively from product to product, thus indicating a similar basic composition for different oak wood samples. Each of the 25 volatile and less-volatile components in this study varied considerably in concentration (Tables 2 to 10, Van Jaarsveld et al., 2009a; Tables 1 to 4, Van Jaarsveld et al., 2009b; Tables 1 to 6, Van Jaarsveld et al., 2009c). Although the concentration of the individual wood-imparted compounds varied, with some possibly lower than their detection threshold limits, their synergistic action yields unique and detectable flavours (Singleton, 1995). The ranges observed for most of the different samples were due to the effects or influences of the different treatments applied.

Compounds not present in unwooded pot-still brandy, but extracted into spirits upon wood treatment and, 


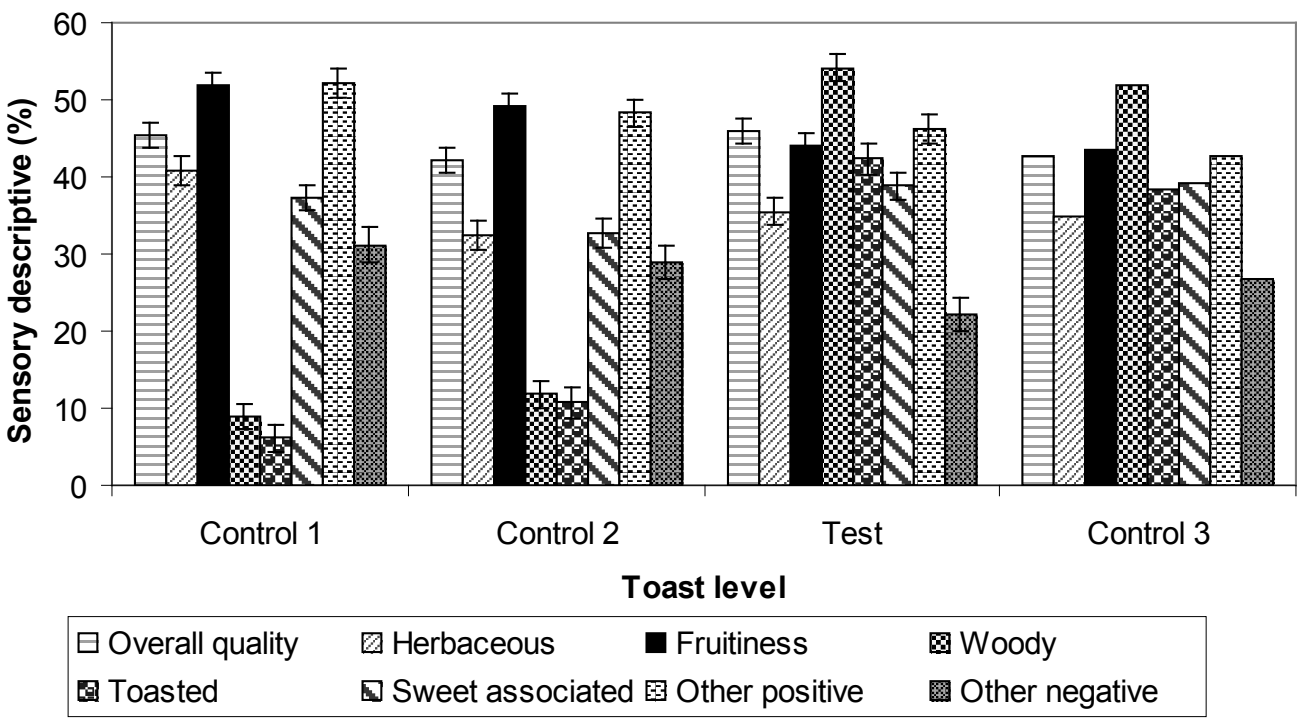

FIGURE 5

Sensory descriptors (overall quality, herbaceous, fruitiness, woody, toasted, sweet associated, other positive and other negative) of eight-month matured pot-still brandy from oak extracts prepared from chips of different species of oak (American and French) obtained from a cooper and subjected to various treatments. Open concentration of extracts was performed in a 5 L flask on a heating mantle. Reduced pressure concentration was performed under vacuum on a rotavap. Extractions were performed in either water or ethanol medium. Oak toast levels: untoasted, medium and heavy. Test samples were stored at room temperature and control 3 was stored at below $0^{\circ} \mathrm{C}$ for eight months. Control 1: $55 \%$ (v/v) neutral wine spirits with no extract, stored at room temperature. Control 2: $55 \%(\mathrm{v} / \mathrm{v})$ neutral wine spirits with no extract, stored below $0{ }^{\circ} \mathrm{C}$. Only the $65 \%$ concentration level was considered in the statistical evaluation.

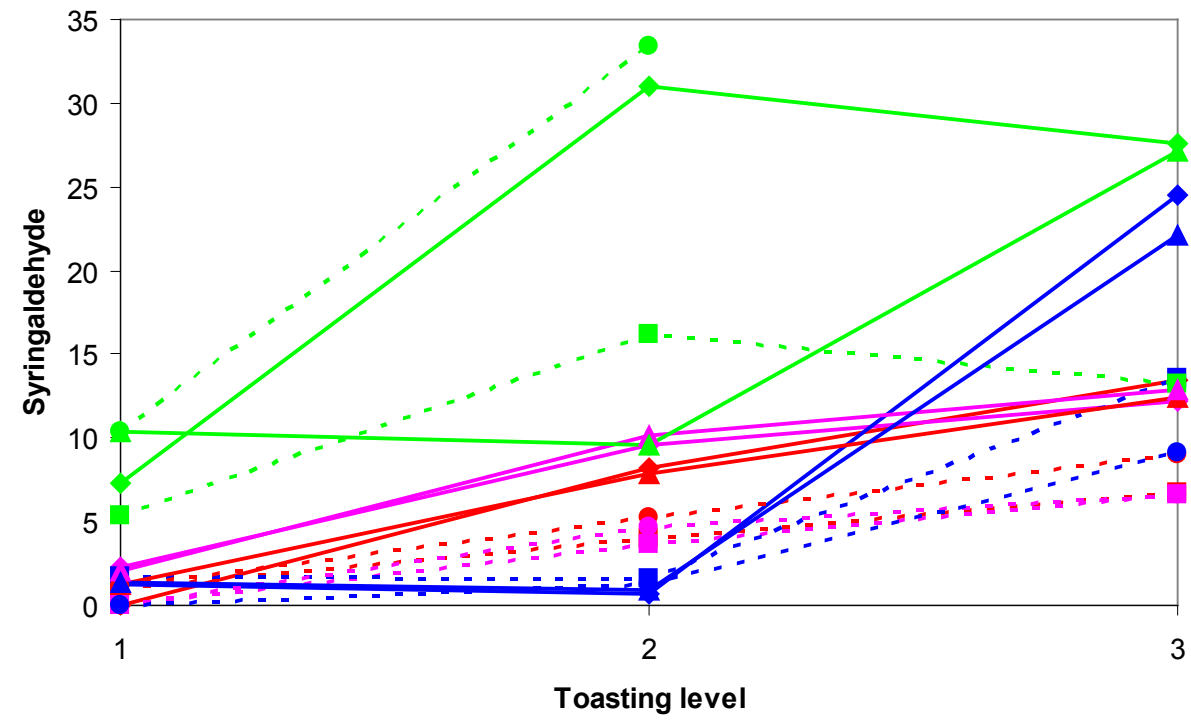

\begin{tabular}{|c|c|c|}
\hline- & $=-$ - C_AO_WA & $-\rightarrow-$ \\
\hline$\sim$ S_AO_EtOH_O & - - - S_AO_WATER_O $\longrightarrow$ S_P & -1 \\
\hline - C_AO & - - - - C_AO_WATER_Cl $\longrightarrow$ C_FO_EtOH_Cl & $--0--$ C_ \\
\hline 1 & $\longrightarrow$ S_FO_EtOH_Cl & FO_WATER_ \\
\hline
\end{tabular}

\section{FIGURE 6}

Treatment interactions between the treatments supplier, oak type, extraction medium and extraction type for the chemical descriptor syringaldehyde in unmatured brandy samples. 1, untoasted (cooper) or special (American oak from commercial supplier) or lightly toasted (French oak from commercial supplier); 2, medium or premium; 3, heavy toast (cooper and French oak from commercial supplier) or toasted (American oak from commercial supplier). Abbreviations: C, cooper; S, commercial supplier; AO, American oak; FO, French oak; EtOH, ethanol; O, open; and Cl, closed. American and French oak chips, obtained from a cooper and a commercial supplier and representing different toasting levels, were subjected to different treatments, as described in the legend to Figure 1, to extract the wood components, and stored for eight months at room temperature or below $0^{\circ} \mathrm{C}$. Only the $65 \%(\mathrm{v} / \mathrm{v})$ concentration was considered in the statistical evaluation. 
therefore, essentially products of oak extraction, were 5-methylfurfural, trans- and cis-oak lactones, phenol, $o$-cresol, $p$-cresol, 5-hydroxymethyl furfural, vanillin, protocatechuic acid, $p$-hydroxybenzoic acid, vanillic acid, syringic acid, $p$-coumaric acid, $m$-coumaric acid, ellagic acid, coniferaldehyde, syringaldehyde and sinapaldehyde. The furanes (furfural, 5-methyl furfural), oak lactones, aldehyde phenols (vanillin, syringaldehyde) and volatile phenols (guaiacol, ethyl guaiacol) are four component family groups mostly or entirely derived from oak. These compounds, some of which are considered indicators of wine and spirits ageing in wooden barrels, are either extracted from oak, or are produced by the action of alcohol on the macromolecular structure of oak lignin, produced primarily by ageing and, therefore, increase in concentration during barrel ageing (Onishi et al., 1977; Delgado et al., 1990). Distillates contain no tannins and little total phenol (Singleton, 1995). All new compounds such as furfural, which are not present in distilling wines, may be produced by heat during distillation (Onishi et al., 1977). Furfural has been identified in initial distillates, is considered to be a product of heating, is formed during distillation, particularly pot distillation, but is largely derived from extraction of oak as 5-methylfurfural.

Published data on aromatic aldehydes and acids in aged spirits are generally based on heterogeneous samples, and are incomplete and contradictory at times. Gallic and ellagic acids are some of the more common and predominant compounds in matured and unmatured pot-still brandy prepared with oak wood extracts, but are not the most predominant, as reported by Canas et al. (1999) and Van Jaarsveld et al. (2009a, 2009b, 2009c). The reason for the high concentrations of gallic acid can be explained by its higher diffusion rate as compared to other compounds in oak wood extracts (Canas et al., 1999). Vanillic acid, syringic acid, $p$-coumaric acid and $m$-coumaric acid are present in lower concentrations compared to gallic and ellagic acids, with syringic acid predominating. Puech $(1981,1988)$ also reported $p$-coumaric, syringic and vanillic acids to be present in brandies, with vanillic and syringic acids predominant and syringic acid contents higher than vanillic acid contents. The concentrations of gallic acid in commercial brandies from Spain and other European Union countries aged along the traditional or static criaderas and soleras systems ranged from 0 to $17.43 \mathrm{mg} / \mathrm{L}$ (Giménez et al., 2000).

As also reported by other authors, aromatic phenolic aldehydes, i.e. benzoic (vanillin, syringaldehyde) and cinnamic (coniferaldehyde, sinapaldehyde) aldehydes, were present in all the aged samples, produced by the main process of brandy ageing, viz. hydroalcoholic processes at room temperature (Baldwin et al., 1967; Puech, 1984). Of the phenolic aldehydes, coniferaldehyde, syringaldehyde and sinapaldehyde were predominant. As reported for Armagnac and Cognac (Puech, 1988), the concentrations of aromatic aldehydes (vanillin, syringaldehyde, coniferaldehyde,
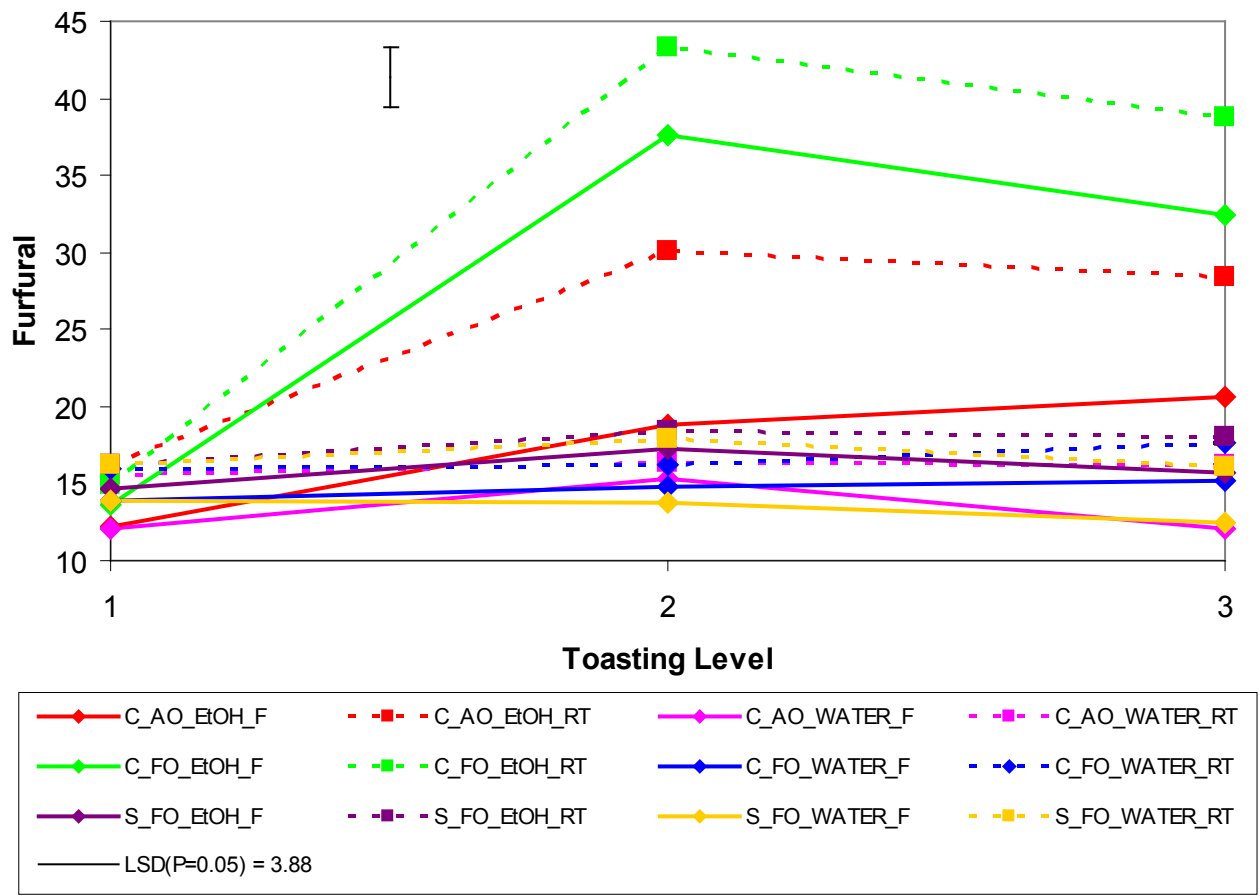

FIGURE 7

Treatment interactions between the treatments supplier, oak type, extraction medium and storage for the chemical descriptor furfural in matured pot-still brandies. 1, untoasted (cooper) or special (American oak from commercial supplier) or lightly toasted (French oak from commercial supplier); 2, medium or premium; 3, heavy toast (cooper and French oak from commercial supplier) or toasted (American oak from commercial supplier). Abbreviations: C, cooper; S, commercial supplier; $\mathrm{AO}$, American oak; FO, French oak; $\mathrm{EtOH}$, ethanol; F, stored below $0^{\circ} \mathrm{C}$; and $\mathrm{RT}$, stored at room temperature. American and French oak chips, obtained from a cooper and a commercial supplier and representing different toasting levels, were subjected to different treatments, as described in the legend to Figure 1, to extract the wood components, and stored for eight months at room temperature or below $0^{\circ} \mathrm{C}$. Only the $65 \%(\mathrm{v} / \mathrm{v})$ concentration was considered in the statistical evaluation. 
sinapaldehyde) in unmatured and matured pot-still brandies were higher than those of the aromatic acids (vanillic and syringic acids) in this study (Van Jaarsveld et al., 2009a, 2009 b, 2009c). The oak wood extracts prepared in this study therefore possess some of the chemical characteristics of spirits aged traditionally in barrels, conferring to pot-still brandies some distinctive properties of barrel-aged brandies. The syringaldehyde concentration varied from 0 to 45.170 $\mathrm{mg} / \mathrm{L}$ in unmatured and matured spirits, coniferaldehyde from 0 to $161.250 \mathrm{mg} / \mathrm{L}$ and sinapaldehyde from 0 to 98.080 $\mathrm{mg} / \mathrm{L}$. The concentrations of aromatic aldehydes in this study correlate with literature values for wood components (Singleton, 1995). Puech (1981) reported syringaldehyde, vanillin, sinapaldehyde and coniferaldehyde concentrations of 1 to $11.4 \mathrm{mg} / \mathrm{L}$ in five- to thirty-year-old Armagnac.

Ratios of the compounds of pot-still brandies prepared with American and French oak wood obtained from a cooper and from commercial suppliers in this study, and rations reported in the literature, are shown in Table 13. Ratios can be indicators of brandy quality. In this study the aromatic acid:aldehyde and lignin-derived aromatic acid ratios in potstill brandies were generally higher in test (stored at room temperature for eight months) as opposed to control samples (stored below $0^{\circ} \mathrm{C}$ for eight months). Possible differences in ratios of compounds in this study and those reported by other authors can be explained by different oak extraction or ageing methods applied. In this study, pot-still brandies were made from extracts prepared from oak chips subjected to different extraction methods, whereas the values reported in the literature are generally from brandies aged along more traditional ways in oak.

In matured pot-still brandy, mostly that prepared with toasted chips, vanillin clearly exceeded the threshold concentrations or organoleptic perception levels in water of $2 \mathrm{mg} / \mathrm{L}, 0.5 \mathrm{mg} / \mathrm{L}$ in $10 \%$ ethanol, and $0.1 \mathrm{mg} / \mathrm{L}$ in $40 \%$ ethanol, as reported by Singleton (1995). Syringaldehyde, but not vanillic acid and syringic acid concentrations, in matured pot-still brandies in this study generally exceeded reported threshold values or organoleptic perception levels of $25 \mathrm{mg} / \mathrm{L}$ (Singleton, 1995) and $15 \mathrm{mg} / \mathrm{L}$ (Puech, 1987). Synapaldehyde did not exceed the reported threshold value of $80 \mathrm{mg} / \mathrm{L}$ (Singleton, 1995). Vanillin is thus well above the sensory threshold level and important to the aroma of matured distilled spirit. The sensory threshold of eugenol, a volatile phenol, is estimated at $0.011 \mathrm{mg} / \mathrm{L}$ in $10 \%$ ethanol and $0.050 \mathrm{mg} / \mathrm{L}$ in $20 \%$ ethanol (Singleton, 1995). Even after eight months' maturation, the concentrations of transoak lactone in this study (Van Jaarsveld et al., 2009a, 2009b, 2009c) were generally below the reported thresholds for the trans form, i.e. about $0.8 \mathrm{mg} / \mathrm{L}$ (Singleton, 1995) and 0.067 $\mathrm{mg} / \mathrm{L}$ (Otsuka et al., 1974). In contrast, Van Jaarsveld et al. (2009a, 2009b, 2009c) found, in the case of cis-oak lactone - generally American oak-prepared and/or commercial samples - concentrations above the thresholds reported by Singleton (1995) of $0.07 \mathrm{mg} / \mathrm{L}$ and Mosedale and Puech (1998) (0.092 to 0.001 by GC-sniffing), but below the threshold of $0.79 \mathrm{mg} / \mathrm{L}$ reported by Otsuka et al. (1974). The concentrations of cis- and trans-oak lactones for potstill brandies in this study ranged from a minimum of 0 to a maximum of 0.838 and 1.980 for the cis-forms and 0.778

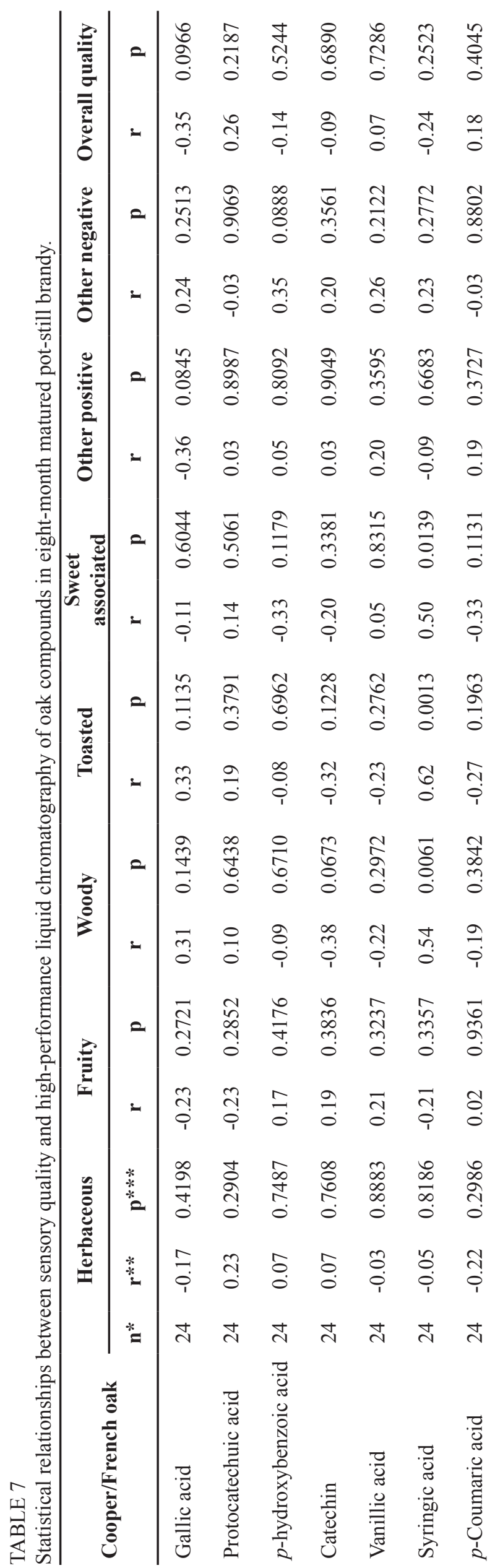



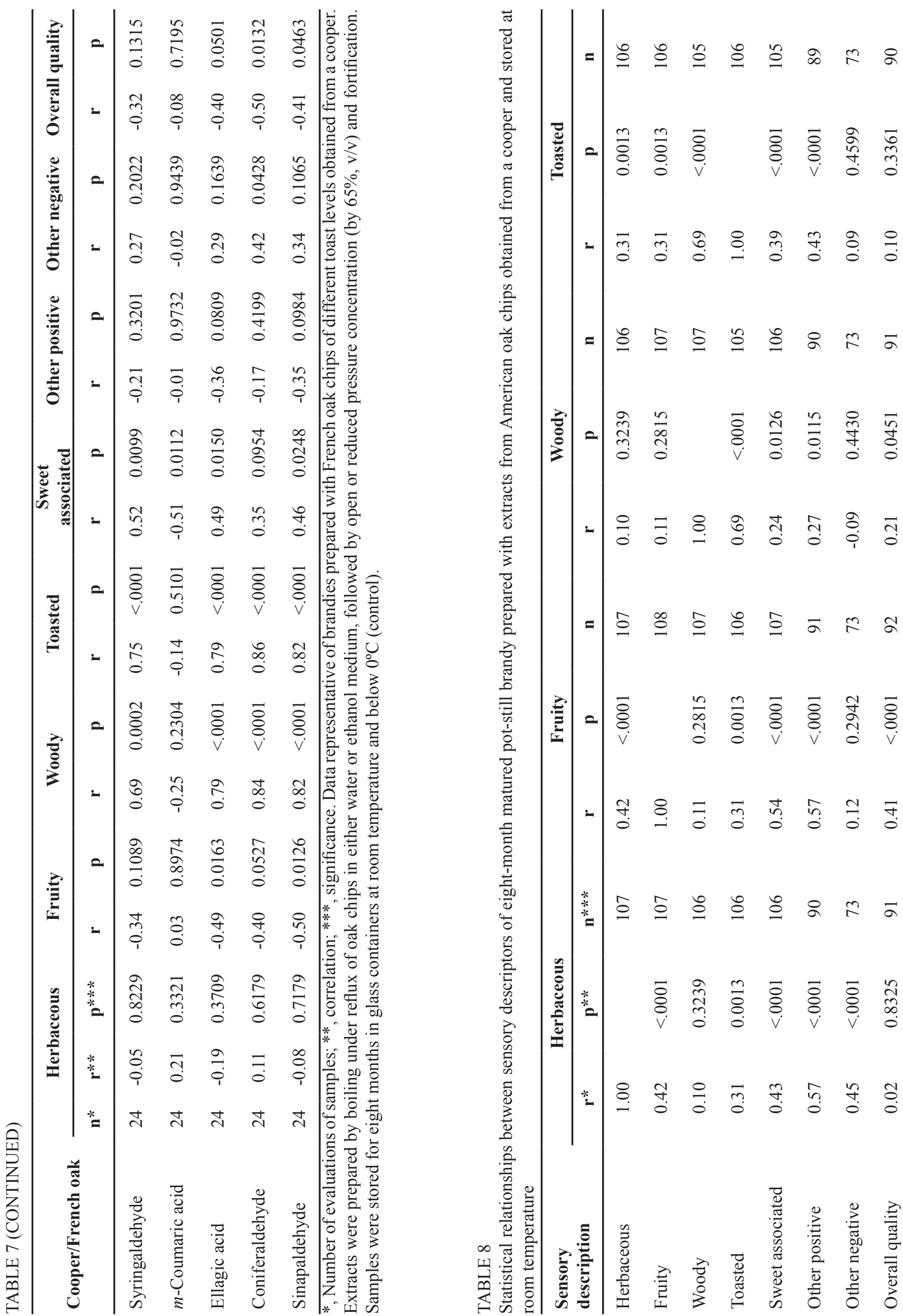


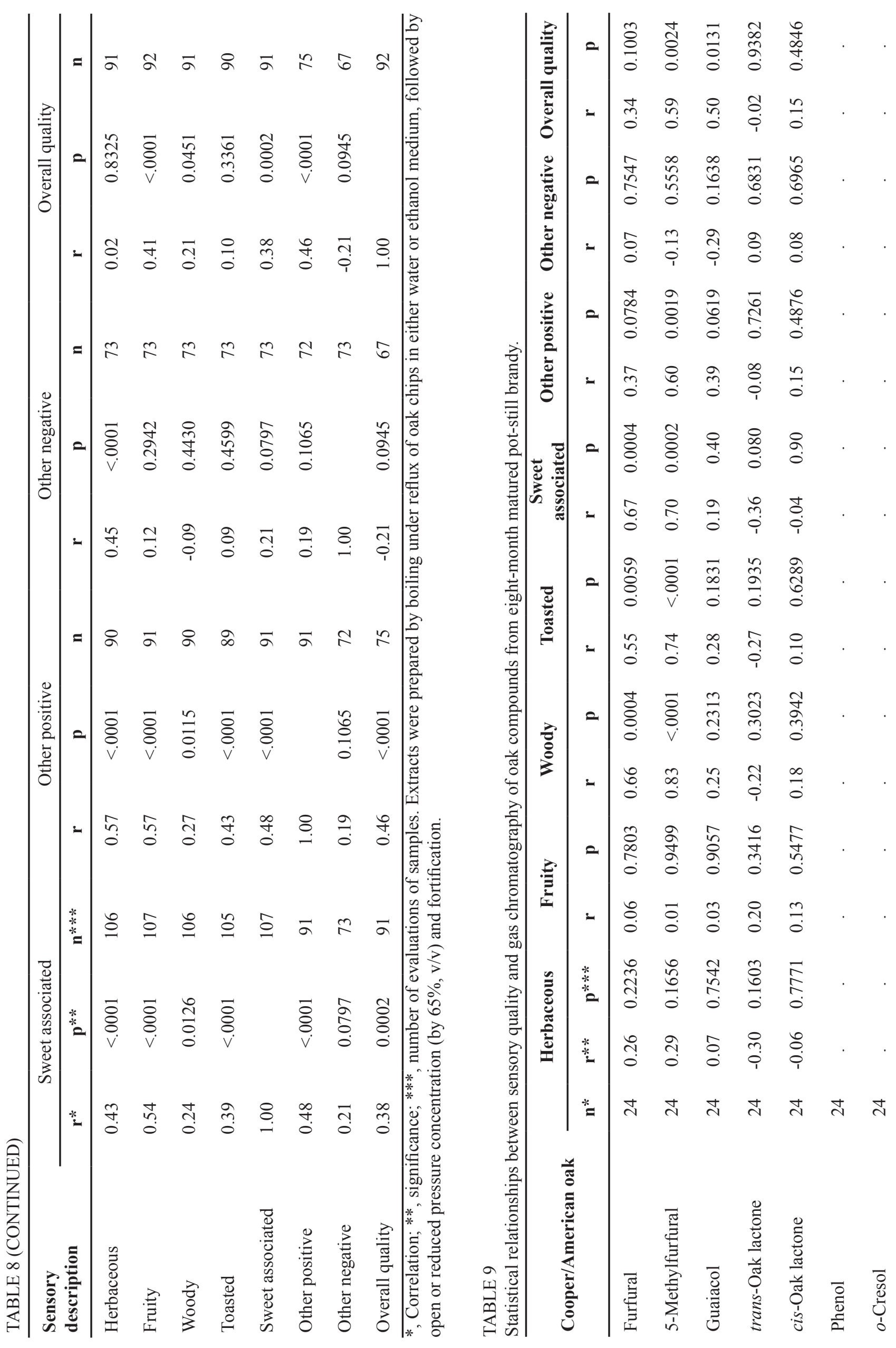




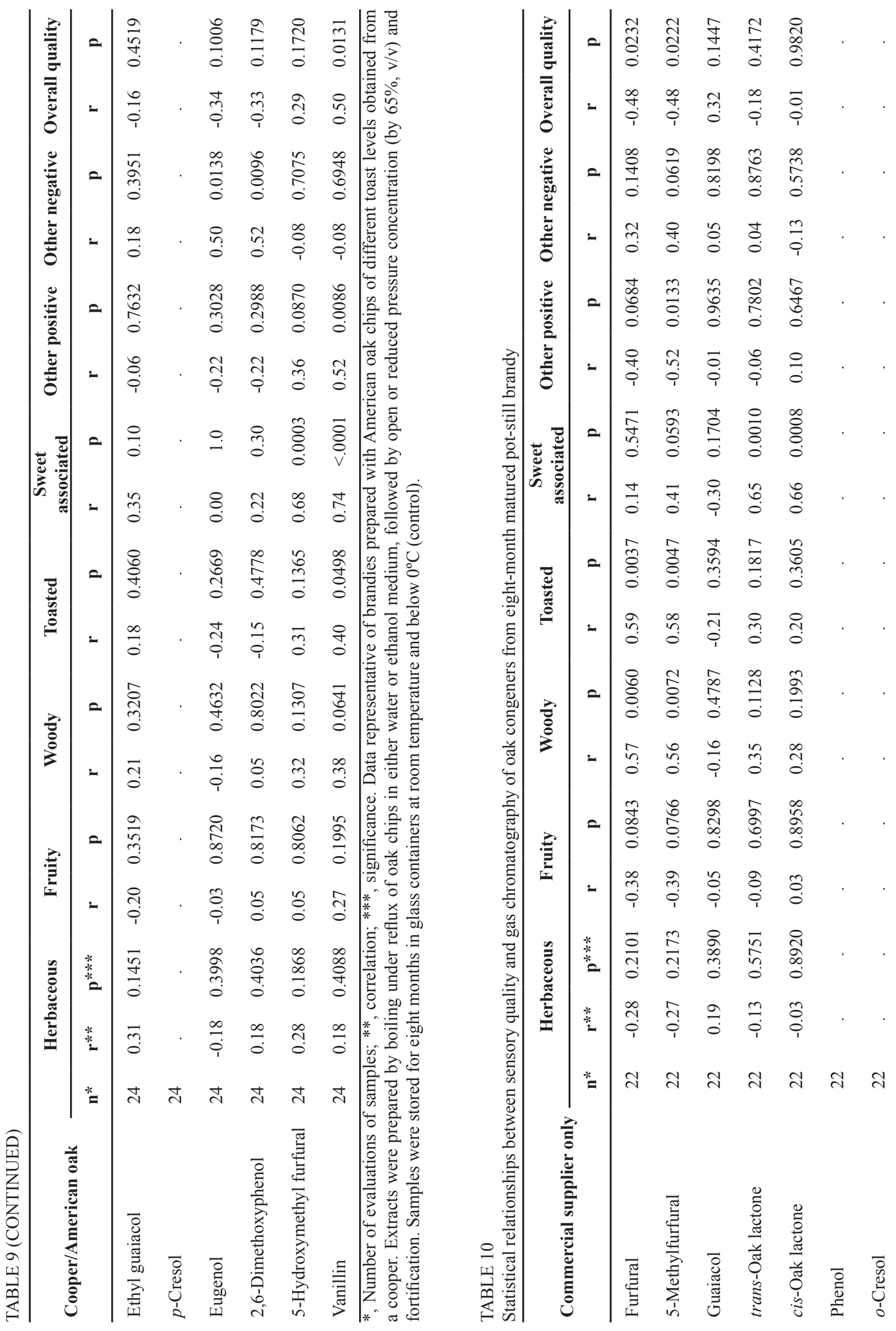




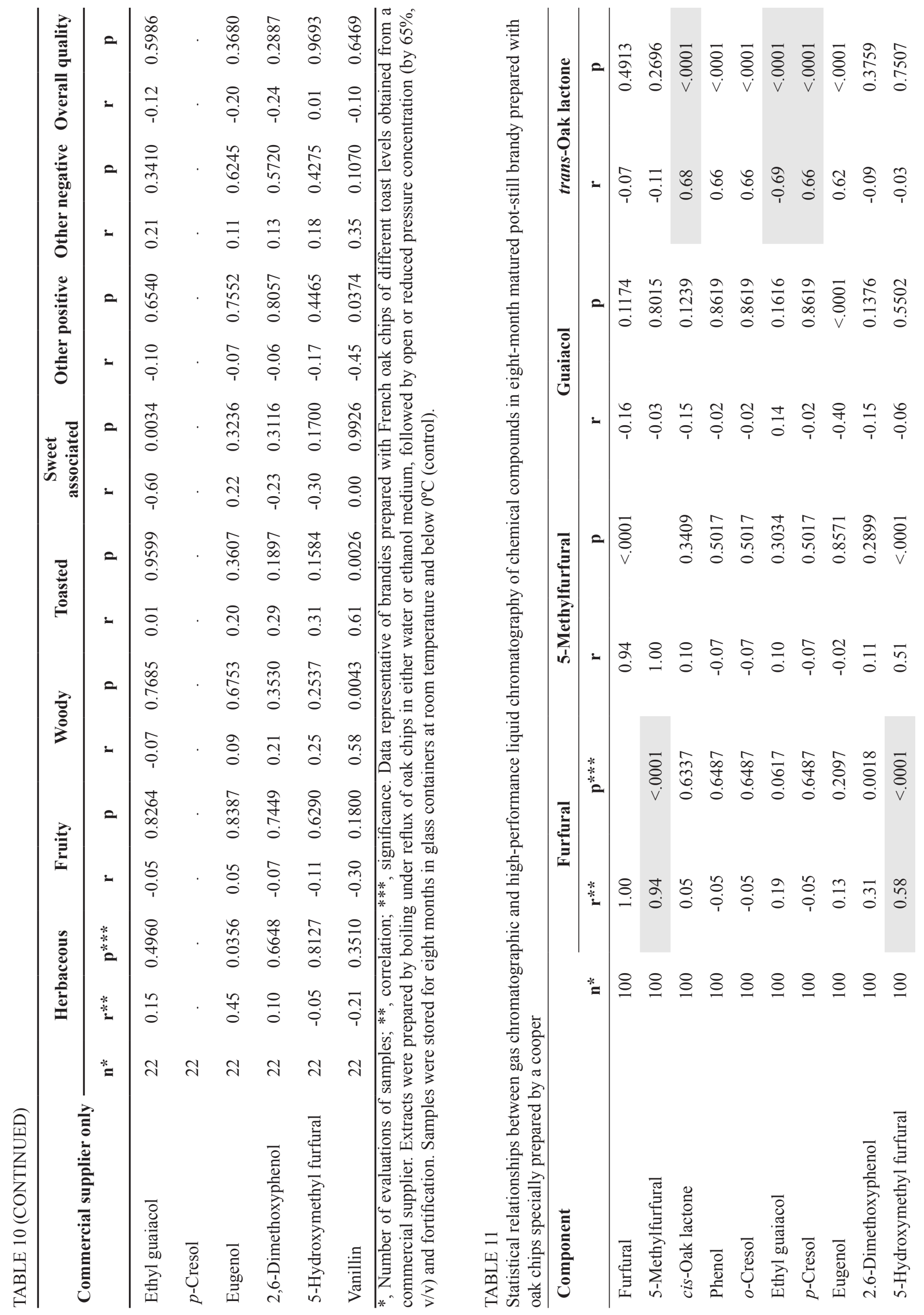




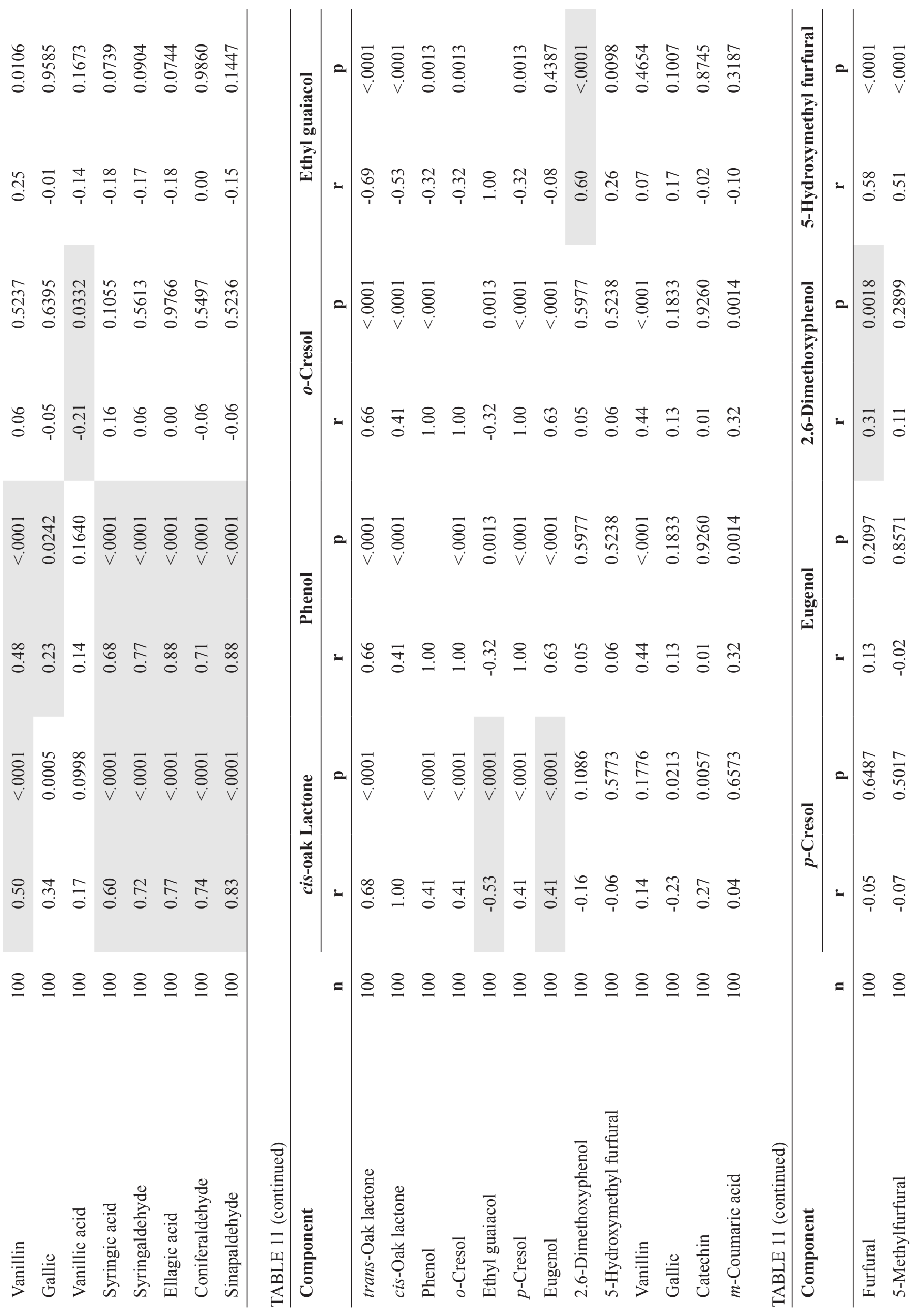




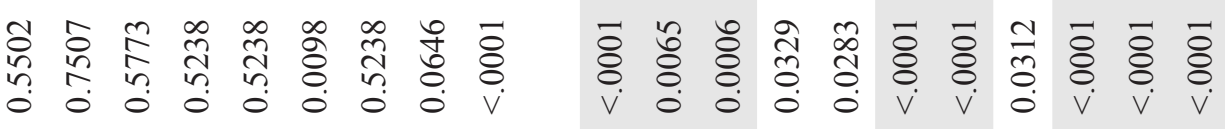

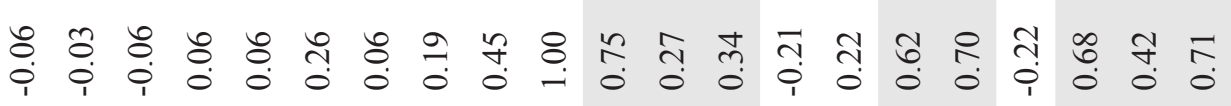

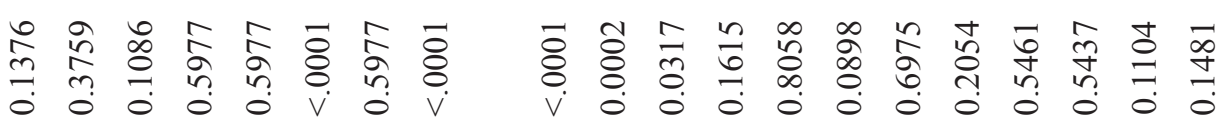

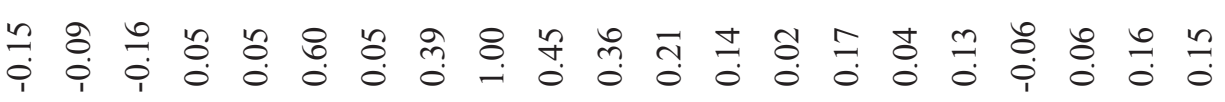

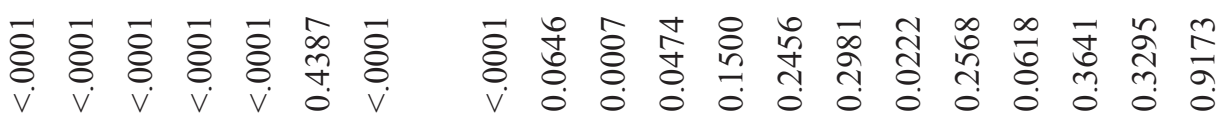

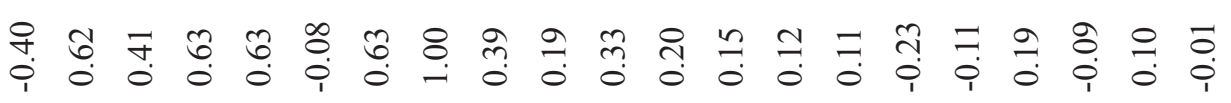

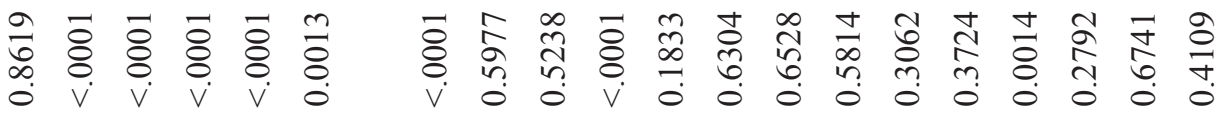

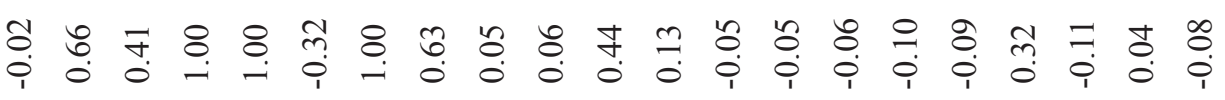

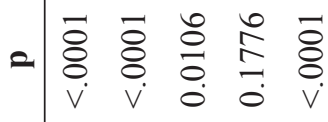

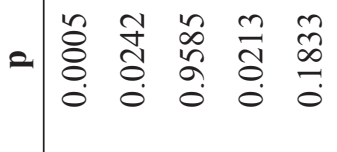

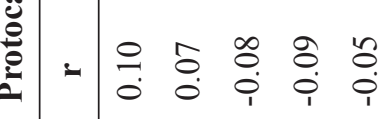

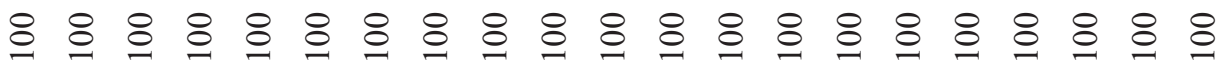

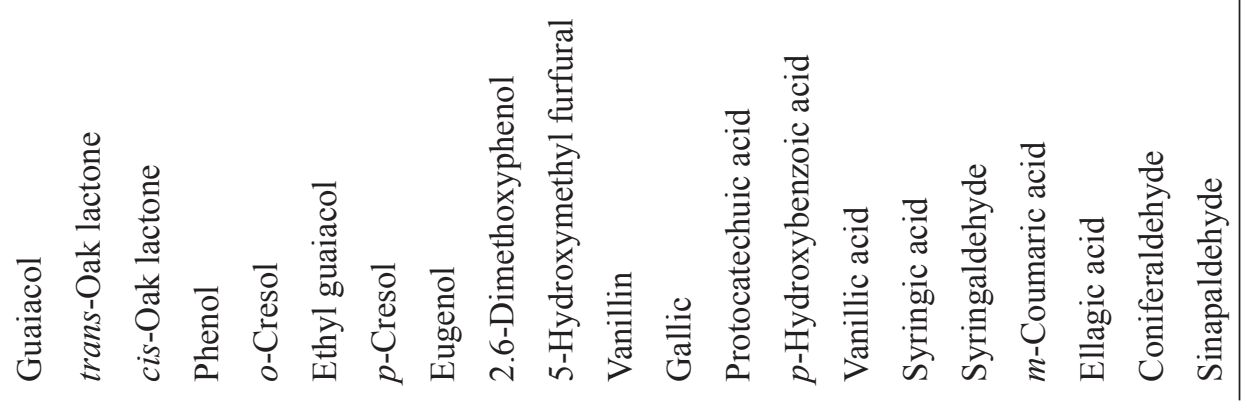




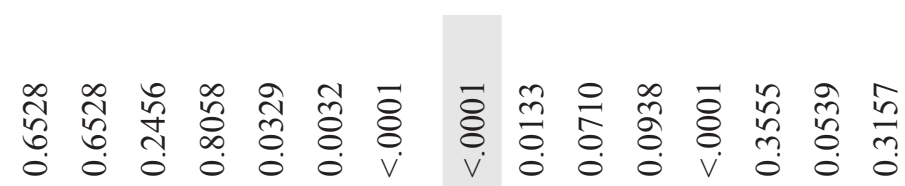

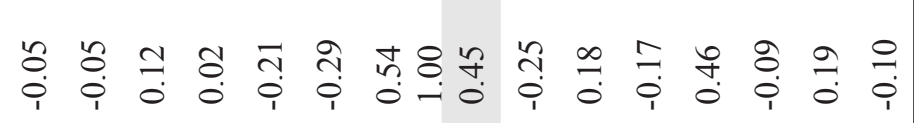

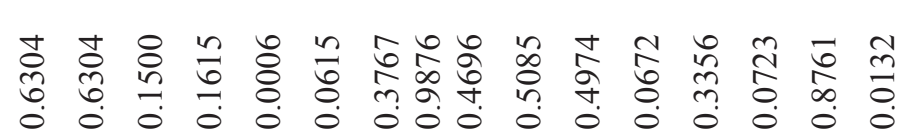

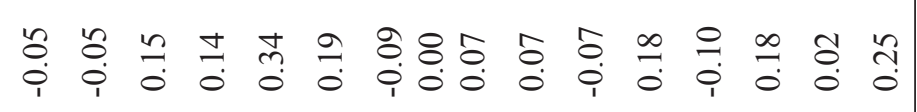

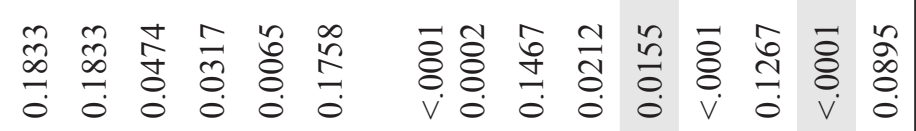

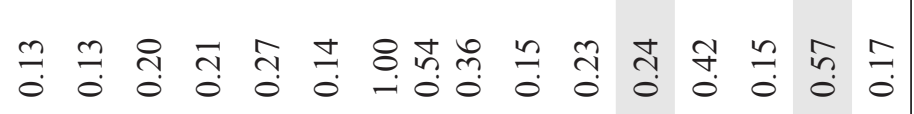

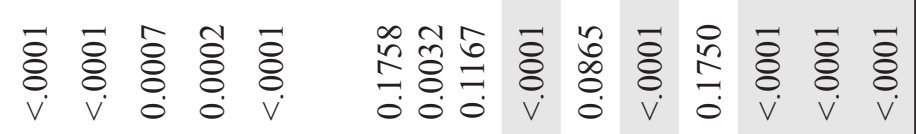

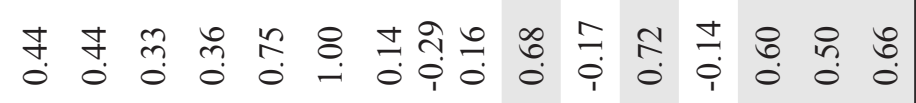

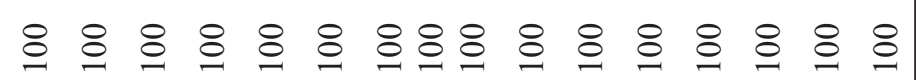

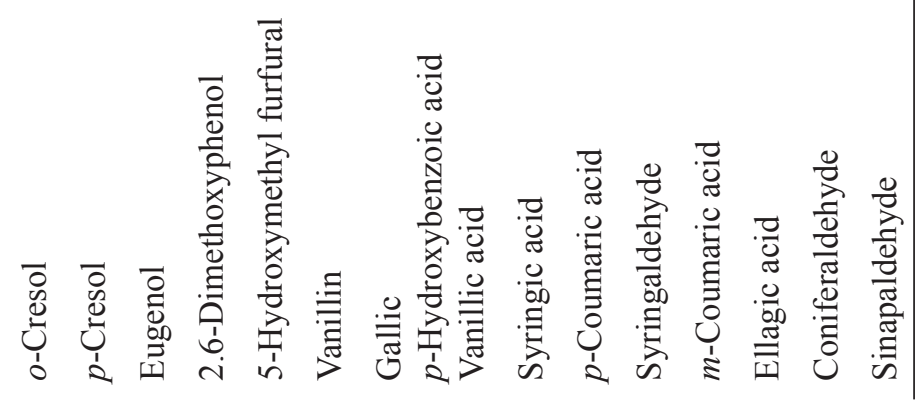

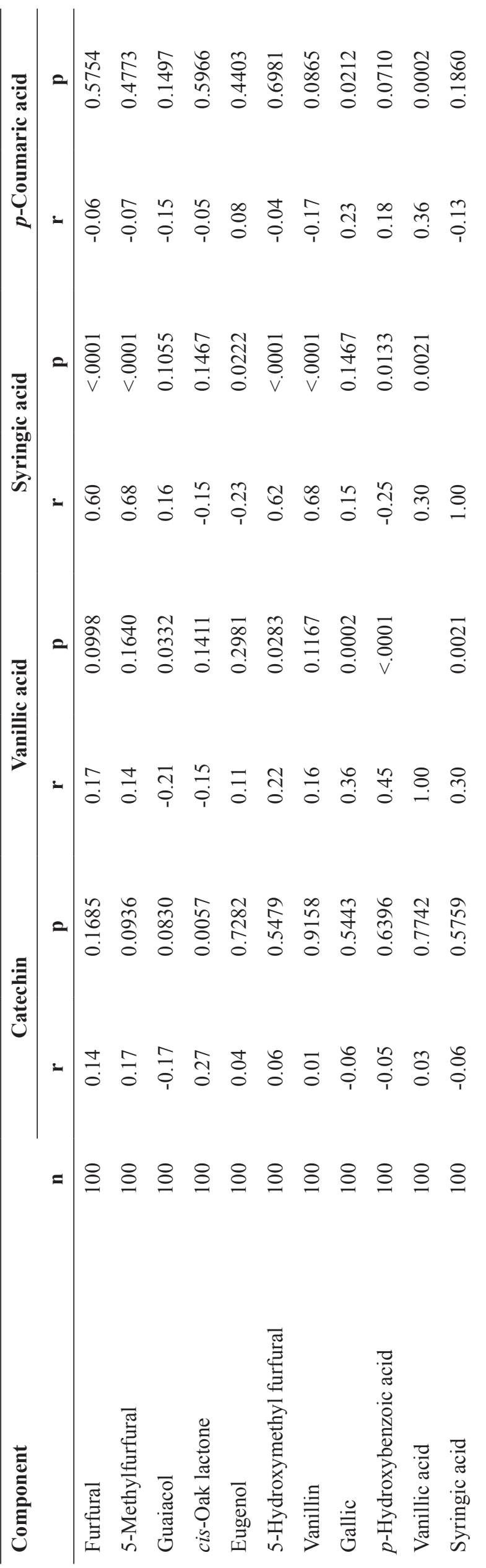




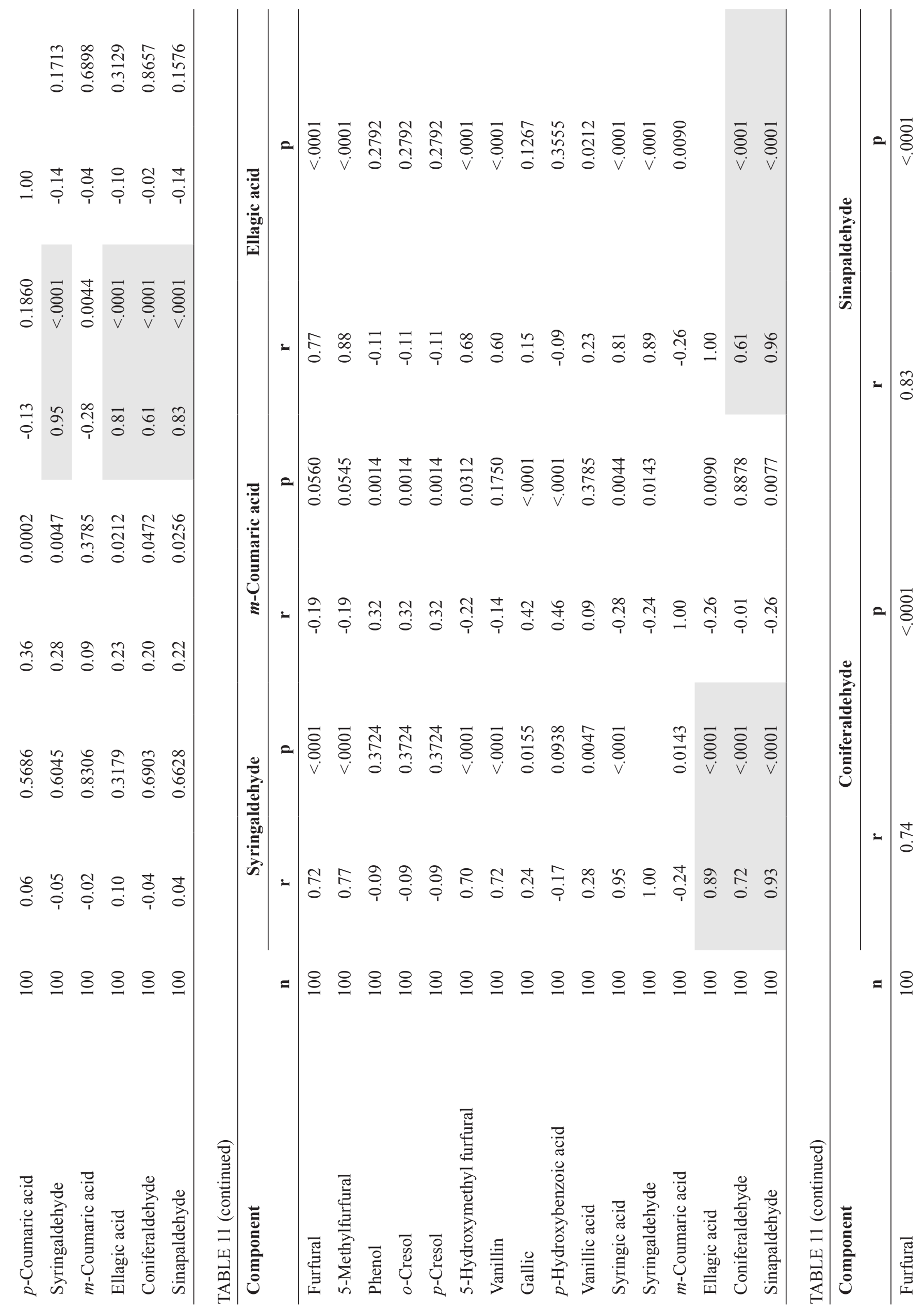




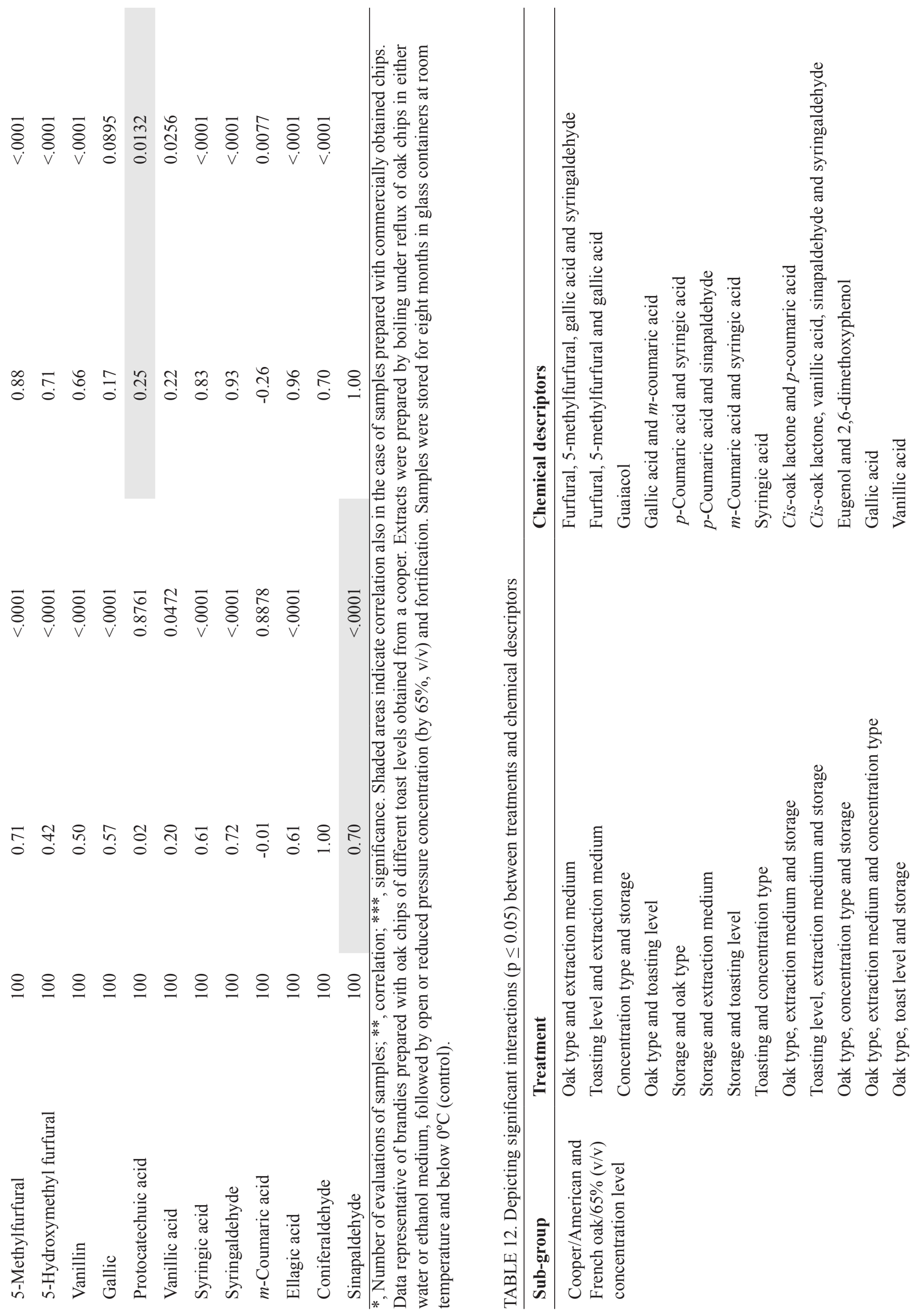



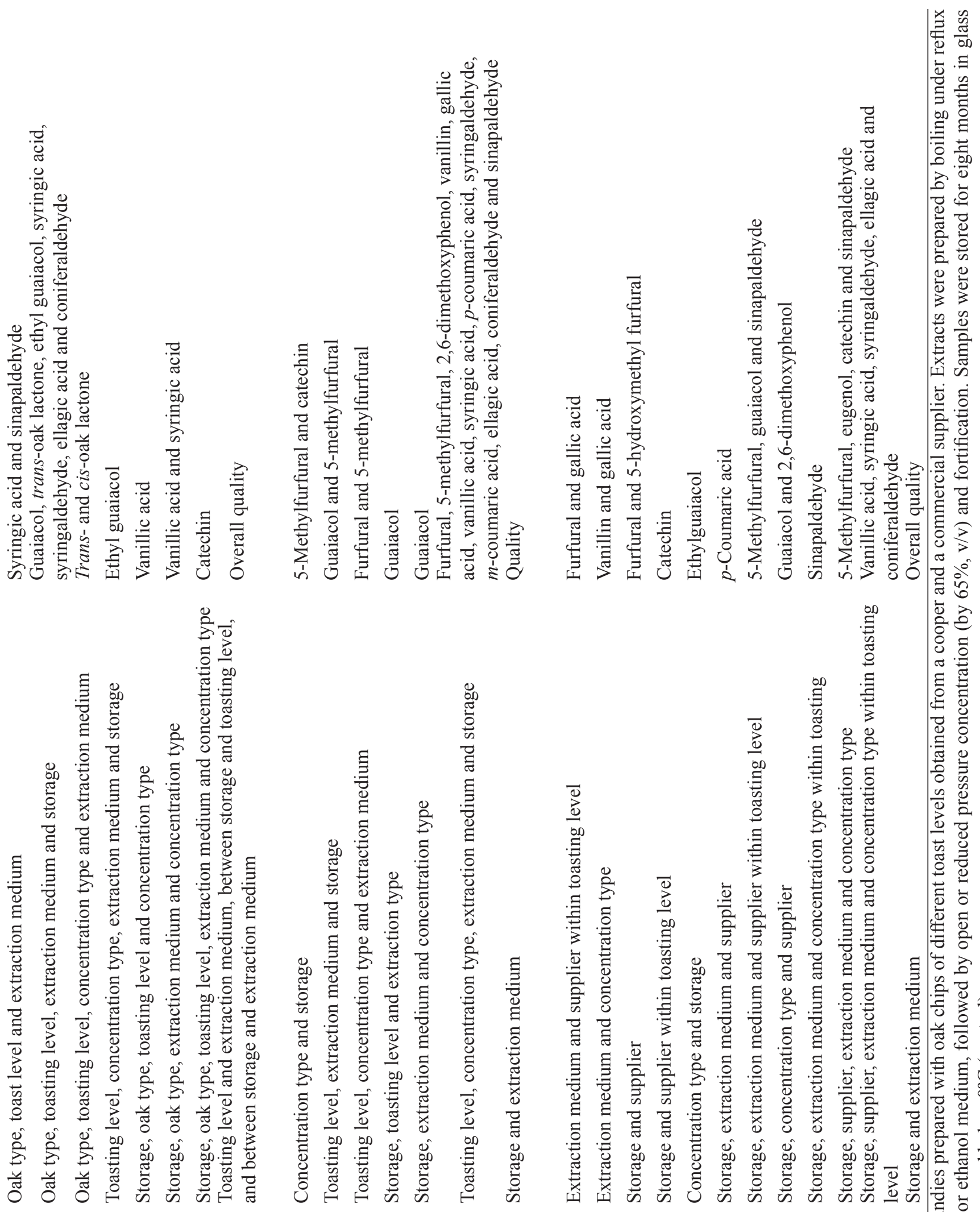


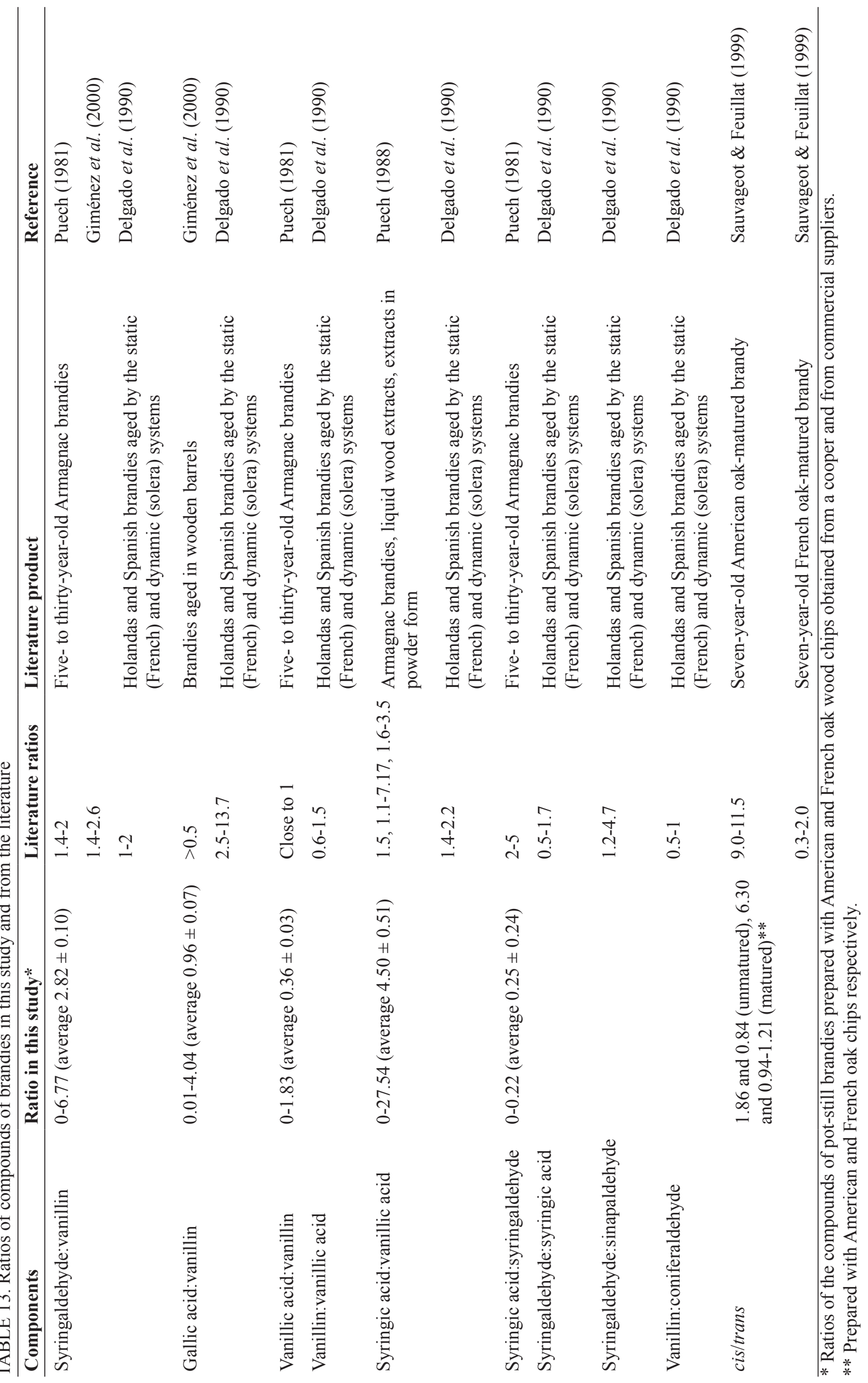


and $1.610 \mathrm{mg} / \mathrm{L}$ for the trans-forms, in unmatured and matured pot-still brandies respectively (Van Jaarsveld et al., 2009a, 2009b, 2009c). These figures are well within the ranges reported by different authors for alcoholic beverages matured in French and American oak barrels (Sauvageot \& Feuillat, 1999). The conversion of a precursor seems to be involved, as different authors have reported different results. The relative proportions of oak lactones vary according to the type of finished product. The type of wood (oak source) used, and seasoning and coopering conditions such as charring, are important factors influencing the concentration of compounds, with reported large differences in oak lactone concentrations (De Smedt \& Liddle, 1978; Sefton et al., 1993; Spillman et al., 2004a; Van Jaarsveld et al., 2009b, 2009c). The use of extracts or oak chips as reported on in this study, as opposed to traditional ageing in wooden casks, is also an important factor that could impact on concentration. A series of different brandies, mostly Eastern European, contained traces to $0.68 \mathrm{mg} / \mathrm{L}$ of the trans, and 0.13 to 1.54 $\mathrm{mg} / \mathrm{L}$ of the cis, forms of lactone. Oak lactone (cis + trans $)$ concentrations of 0.05 to $0.5 \mathrm{mg} / \mathrm{L}$ in French and 1 to 1.670 in American brandies, and 0.05 to $5.2 \mathrm{mg} / \mathrm{L}$ in commercial products (Armagnac, Martinique rum, Bourbon and malt whisky) of unknown age to seventy-three years of age, have been reported (De Smedt \& Liddle, 1978; Sauvageot \& Feuillat, 1999).

The concentrations of compounds in this study can vary greatly from those of other studies due to experimental limitations such as restricted sampling ranges, unspecified oak species, use of wood that is not fresh (air or oven-dried, totally or partially), and lack of relevant data concerning enantiomeric ratios for the stereoisomers, i.e. oak lactones. Different maturation methods (e.g. the use of wooden barrels versus oak chips and/or used barrels versus new barrels) and extraction procedures between studies are also possible causes of variation. Singleton (1995) reported that only about a week is necessary to extract $90 \%$ as much as exhaustive extraction will from chips no larger than $1 \mathrm{~mm}$ in size, whereas this process can take up to one year in wooden barrels. Also, the rates of extraction of compounds differ. Sefton and Spillman (1995) reported that, while some of the coopering-derived compounds were extracted during the first few weeks of maturation in wooden barrels, the cis-oak lactone continued to be extracted over a two-year period. Oak compounds extracting at faster rates therefore will have greater sensory impact on brandies with shorter maturation times, while oak lactones will impact more on flavour in beverages aged for longer periods.

\section{CONCLUSIONS}

From this and earlier articles in this series it is apparent that some maturation characteristics can be induced rapidly in brandy products bottled in glass. The material that induced the highest quality from a sensorial viewpoint was an extract obtained from toasted oak extracted in ethanol medium and concentrated by $65 \%(\mathrm{v} / \mathrm{v})$, the quality of pot-still brandy having been shown to depend on the concentrations and composition of wood-derived congeners. Although French oak and open concentration initially yielded higher quality products, the beneficial effects of these extracts decreased over a maturation period of eight months, at which point the quality was equivalent to that obtained using an extract of American oak concentrated under reduced pressure. That pot-still brandy prepared with oak chips supplied by a cooper fared better than commercial chips implies that detailed knowledge concerning the origins and seasoning of the woods used in brandy manufacture is essential. Although quality in this series of experiments was assessed after treatment with single extracts, and recommendations can, in consequence, be made regarding oak types and treatment combinations, it is likely that even higher quality products will eventually be produced using combinations of practices and extracts. Maturation in glass bottles did not result in continuing improvement in quality, as occurs during ageing in wooden barrels, probably because less oxidation occurs in glass than in barrels. Furthermore, although products bottled in glass attain an aged character quickly (from the added oak extract), they do not continue to change in the same manner as do products in barrels, where slow extraction from the wood continues over the entire period that the product remains in the barrel. Consequently, the complexities of brandy products aged in glass may differ in character from those of brandies aged slowly in wooden barrels. Direct comparison between products that acquired aged character in glass, and brandy aged in wooden barrels, was excluded from the protocol of this research, but should be included in future work, as should combinations of oak treatment and traditional barrel maturation.

Research should also focus on synergy and complementarity between the aromatic molecules of brandy and oak, and on the production and ageing conditions that will permit improved control over the delivery of extractables, thereby increasing the likelihood that the various types of aroma can be balanced to achieve the best results. Barrel ageing has improved brandy quality tremendously over the past several centuries. However, guidelines concerning improved ways of using oak are constantly evolving. Only a full understanding of ageing, and of the conditions necessary to bring about the best complementary association of components in brandy and oak, will enable the very best brandies to be produced consistently. Knowledge of the important compounds, and the development of fast and reliable methods to determine their concentrations in wood, will also influence future choices of raw materials. Through this knowledge, the industry may truly steer towards better control of its products, to the extent that complete automation may become feasible. As our understanding of these processes develops, so will our ability to manage oak maturation to maximum advantage.

\section{LITERATURE CITED}

Anonymous, 1995. American oak. Wynboer, September, 52.

Baldwin, S., Black, R.A., Andreasen, A.A. \& Adams, S.L., 1967. Aromatic congener formation in maturation of alcoholic distillates. J. Agr. Food Chem. 15, 381-385

Canas, S., Leandro, M.C., Spranger, M.I. \& Belchior, A.P., 1999. Low molecular weight organic compounds of chestnut wood (Castanea sativa L.) and corresponding aged brandies. J. Agric. Food Chem. 47, 5023-5030. 
Cerdán, T.G., Goñi, D.T. \& Azpilicueta, C.A., 2002. Changes in the concentration of volatile oak compounds and esters in red wine stored for 18 months in re-used French oak barrels. Aust. J. Grape Wine Res. 8, 140-145.

Clyne, J., Conner, J.M., Paterson, A. \& Piggott, J.R., 1993. The effect of cask charring on Scotch whisky maturation. Int. J. Food Sci. Tech. 28, 6981.

De Beer, D., Joubert, E., Marais, J. \& Manley, M., 2008. Effect of oxygenation during maturation on phenolic composition, total antioxidant capacity, colour and sensory quality of Pinotage wine. S. Afr. J. Enol. Vitic. $29,13-25$.

Delgado, T., Gómez-Cordovés, C. \& Villarroya, B., 1990. Relationship between phenolic compounds of low molecular weight as indicators of the aging conditions and quality of brandies. Am. J. Enol. Vitic. 41, 342-345.

De Smedt, P. \& Liddle, P.A.P., 1978. Research note: Identification of 1,1'diethoxypropan-2-one in spirits aged in wood. Am. J. Enol. Vitic. 29, 286288.

Feuillat, F., Keller, R., Sauvageot, F. \& Puech, J.-L., 1999. Characterisation of French oak cooperage (Quercus robur L., Quercus petaea Liebl.). Research of the study group on barrel-ageing burgundy wines. Am. J. Enol. Vitic. 50, 513-518.

Francis, I.J., Sefton, M.A. \& Williams, P.J., 1992. A study by sensory descriptive analysis of the effects of oak origin, seasoning, and heating on the aromas of oak model wine extracts. Am. J. Enol. Vitic. 43, 20-30.

Giménez, R., Villalón, M., López, H., Navarro, M., Cabrera, C., Olalla, M., Quesada, J.J. \& López, M.C., 2000. Determination of gallic acid in commercial brandies using high performance liquid chromatography. Cienc. Tecnol. Aliment. 3, 13-20.

Godden, P.W., Pollnitz, A.P., Osicka, S., Sykes, M., Liacopoulos, D., Pardon, K.H., Spillman, P.J., Gawel, R., Jones, G.P., Skluoumounis, G.K. \& Sefton, M.A., 1999. Measuring desirable oakwood components in wine. In: Blair, R.J., Sas, A.N., Hayes, P.F. \& Høj, P.B. (eds). Proc. 10 ${ }^{\text {th }}$ Australian Wine Ind. Tech. Conf., 2-5 August 1998, Sydney, New South Wales, Australia. pp. $121-124$.

Gómez-Cordovés, C. \& Bartolomé, B., 1999. Role of simple lignin phenolics in spirits (brandies and cognac) aged in oak wood. Recent Res. Devel. Agricultural \& Food Chem. 3, 423-433.

Hale, M.D., McCafferty, K., Larmie, E., Newton, J. \& Swan, J.S., 1999. The influence of oak seasoning and toasting parameters on the composition and quality of wine. Am. J. Enol. Vitic. 50, 495-502.

Jindra, J.A. \& Gallander, J.F., 1987. Effect of American and French oak barrels on the phenolic composition and sensory quality of Seyval blanc wines. Am. J. Enol. Vitic. 38, 133-138.

Jung, D-M., De Ropp, J.S. \& Ebeler, S.E., 2000. Study of interactions between food phenolics and aromatic flavours using one- and twodimensional 1H NMR spectroscopy. J. Agric. Food Chem. 48, 407-412.

Lebrun, L., 1991. Used barrels and resulting aromas. Aust. Grapegrow. Winemaker, 355, July, 21.

Lee, K.-Y.M., Paterson, A. \& Piggott, J.R., 2000. Perception of whiskey flavour reference compounds by Scottish distillers. J. Inst. Brew. 106, $203-$ 208.

Li, P. \& Hardy, K., 1999. Characterization and classification of Ohio wines using multivariate data analysis. J. Wine Res. 10, 197-206.

Litchev, V., 1989. Influence of oxidation processes on the development of the taste and flavor of wine distillates. Am. J. Enol. Vitic. 40, 31-35.

Masson, E., Baumes, R., Le Guernevé, C. \& Puech, J-L., 2000. Identification of a precursor of $\beta$-methyl- $\gamma$-octalactone in the wood of sessile oak (Quercus petraea (Matt.) Liebl.). J. Agric. Food Chem. 48, 4306-4309.
Masson, G., Guichard, E., Fournier, N. \& Puech, J-L., 1995. Stereoisomers of $\beta$-methyl- $\gamma$-octalactone. II. Contents in the wood of French (Quercus robur and Quercus petraea) and American (Quercus alba) oaks. Am. J. Enol. Vitic. 46, 424-428.

Mosedale, J.R. \& Puech, J-L., 1998. Wood maturation of distilled beverages. Trends in Food Sci. Techn. 9, 95-101.

Onishi, M., Guymon, J.F. \& Crowell, E.A., 1977. Changes in some volatile constituents of brandy during aging. Am. J. Enol. Vitic. 28, 152-158.

Otsuka, K-I., Zenibayashi, Y., Itoh, M. \& Totsuka, A., 1974. Presence and significance of two diastereomers of $\beta$-methyl- $\gamma$-octalactone in aged distilled liquors. Agr. Biol. Chem. 38, 485-490.

Piggott, J.R., Conner, J.M., Paterson, A. \& Clyne, J., 1993. Effects on Scotch whiskey composition and flavour of maturation in oak barrels with varying histories. Int. J. Food Sci. Tech. 28, 303-318.

Puech, J-L., 1981. Extraction and evolution of lignin products in Armagnac matured in oak. Am. J. Enol. Vitic. 32, 111-114.

Puech, J-L., 1984. Characteristics of oak wood and biochemical aspects of Armagnac aging. Am. J. Enol. Vitic. 35, 77-81.

Puech, J-L., 1987. Extraction of phenolic compounds from oak wood in model solutions and evolution of aromatic aldehydes in wines aged in oak barrels. Am. J. Enol. Vitic. 38, 236-238.

Puech, J-L., 1988. Phenolic compounds in oak wood extracts used in the ageing of brandies. J. Sci. Food Agric. 42, 165-172.

Reid, K.J.G. \& Swan, J.S., 1993. Assessment of Scotch whiskey quality by pyrolysis-mass spectometry and the subsequent correlation of quality with the oak wood cask. J. Anal. Appl. Pyrol. 25, 49-62.

SAS, 2000. SAS/STAT Users Guide, Version 8, First Edition, Volume 2. SAS Institute Inc., Cary, NC, USA.

Sauvageot, F. \& Feuillat, F., 1999. The influence of oak wood (Quercus robur L., Q. petraea Liebl.) on the flavor of Burgundy Pinot noir. An examination of variation among individual trees. Am. J. Enol. Vitic. 50, $447-455$.

Sefton, M.A. \& Spillman, P.J., 1995. The influences of oak, coopering heat and microbial activity on oak-derived wine aroma. In: Stockley, C.S., Sas, A.N. Johnstone, R.S. \& Lee, T.H. (eds). Proc. $9^{\text {th }}$ Aust. Wine Ind. Tech. Conf., 16-19 July 1995, Adelaide, South Australia. pp. $66-71$.

Sefton, M.A., Spillman, P.J., Pocock, K.F., Francis, L.L. \& Williams, P.J., 1993. The influence of oak origin, seasoning, and other industry practices on the sensory characteristics and composition of oak extracts and barrel-aged white wines. Aust. Grapegrow. Winemaker 355, July, 17-25.

Shapiro, S.S. \& Wilk, M.B., 1965. An analysis of variance test for normality (complete samples). Biometrika 52, 591-611.

Singleton, V.L., 1974. Some aspects of the wooden container as a factor in wine maturation. In: Dinsmoor Webb, A. (ed). Chemistry of wine making. Advances in Chemistry Series, 137. American Chemical Society, Washington D.C. pp. $254-277$.

Singleton, V.L., 1995. Maturation of wines and spirits: comparisons, facts, and hypothesis. Am. J. Enol. Vitic. 46, 98-115.

Spillman, P.J., Sefton, M.A. \& Gawel, R., 2004a. The effect of oak wood source, location of seasoning and cooperage on the composition of volatile compounds in oak-matured wines. Aust. J. Grape Wine Res. 10, 216-226.

Spillman, P.J., Sefton, M.A. \& Gawel, R., 2004b. The contribution of volatile compounds derived during oak barrel maturation to the aroma of a Chardonnay and Cabernet Sauvignon wine. Austr. J. Grape \& Wine Res. $10,227-235$. 
Suomalainen, H. \& Nykänen, L., 1972. Formation of aroma compounds in alcoholic beverages. Wallerst. Lab. Comm., XXXV, 185-198.

Van Jaarsveld, F.P., Hattingh, S., Minnaar, P. \& Blom, M., 2009a. Rapid induction of ageing character in brandy products - Part I. Effects of extraction media and preparation conditions. S. Afr. J. Enol. Vitic. 30, 1-15.

Van Jaarsveld, F.P., Hattingh, S. \& Minnaar, P., 2009b. Rapid induction of ageing character in brandy products - Part II. Influence of type of oak. S. Afr. J. Enol. Vitic. 30, 16-23.

Van Jaarsveld, F.P., Hattingh, S. \& Minnaar, P., 2009c. Rapid induction of ageing character in brandy products - Part III. Influence of and level of toasting. S. Afr. J. Enol. Vitic. 30, 24-37.
Venter, W.P. 1994. Faktore wat brandewynveroudering beïnvloed en die belangrikste reaksies wat daartydens plaasvind. Wynboer, May, 12-14.

Wilker, K.L. \& Gallander, J.F., 1988. Comparison of Seyval blanc wine aged in barrels and stainless steel tanks with oak chips. Am. J. Enol. Vitic. $39,38-43$.

Williams, A.A., 1983. The flavours of distilled beverages: what conclusions can be drawn from the symposium, and what can flavour research offer the spirit industry for the future? In: Piggott, J.R. (ed.). Flavour of distilled beverages: origin and development. Ellis Horwood Limited, Chichester. pp. $265-274$. 